\title{
Coordination, cooperation and collaboration in relief supply chain management
}

\author{
Christian Wankmüller ${ }^{1} \cdot$ Gerald Reiner $^{2}$
}

Published online: 24 September 2019

(C) The Author(s) 2019

\begin{abstract}
In recent years, an increasing number of natural and man-made disasters has demonstrated that a working relief supply chain management (RSCM) is crucial in order to alleviate the suffering of the affected population. Coordination, cooperation and collaboration within RSCM is essential for overcoming these destructive incidents. This paper explores the research undertaken in recent years, focusing on coordination, cooperation and collaboration in the field of supply chain management (SCM) and RSCM in order to provide unique definitions of these concepts taking the disaster setting into consideration. A systematic literature review including 202 academic papers published from 1996 onwards in top journals dealing with commercial supply and relief supply chain coordination, cooperation and collaboration is applied. In order to answer the underlying research questions in a proper way, a descriptive analysis and qualitative and quantitative content analysis of the papers are conducted. Descriptive results indicate that RSCM coordination, cooperation and collaboration have increasingly shifted into the focus of scientific research since 2001/2004 (i.e., 9/11 and the Indian Ocean Tsunami). Based on the qualitative content analysis, clear definitions of the terms coordination, cooperation and collaboration in SCM and RSCM were elaborated. The research landscape, as a result of the quantitative content analysis, allowed the identification of three issues that need to be addressed in future research work.
\end{abstract}

Keywords Relief supply chain management · Coordination · Cooperation · Collaboration $\cdot$ Systematic literature review

Christian Wankmüller

Christian.Wankmueller@aau.at

Gerald Reiner

gerald.reiner@wu.ac.at

1 Department of Production Management and Business Logistics, Universitaet Klagenfurt, Universitätsstraße 65-67, 9020 Klagenfurt, Austria

2 Department of Information Systems and Operations, Vienna University of Economics and Business, Welthandelsplatz 1, 1020 Vienna, Austria 


\section{JEL Classification M19}

\section{Introduction}

Disasters of recent years have demonstrated that a working relief supply chain management (RSCM) is essential in order to optimally satisfy beneficiaries' needs and to ensure efficient long-term recovery after disasters strike (van Wassenhove 2006; Kovács and Spens 2007). According to Thomas and Kopczak (2005), relief supply chains primarily incorporate the process of planning, implementing and controlling a cost-effective and efficient flow and storage of materials, goods and information from the point of origin to the point of consumption, i.e. the disaster area, in order to alleviate the suffering of the affected population. Implementing and controlling such a cost-effective and efficient flow of relief items requires the structured coordination of specified activities and cooperation between stakeholders in order to realize humanitarian objectives within several stages of RSCM. The common structure of representing RSCM follows a four stages model comprising mitigation, preparation, response and recovery stages (van Wassenhove 2006). Each one of these phases includes core operations, such as relief items procurement, transportation and warehousing, to efficiently meet beneficiaries' needs in disaster regions.

High levels of coordination, cooperation and collaboration between involved aid providers are needed for efficient logistics processes in items procurement, transport and warehousing. In the immediate response phase, coordination, cooperation and collaboration is firstly required when non-governmental organizations (NGOs) assess the beneficiaries' needs by sending field assessment and coordination teams into the disaster area (Kovács and Spens 2007). Based on reported demand quantities, relief organizations obtain goods from suppliers located close to the disaster region or from international sources (Roh et al. 2013). Relief items transportation, as another field where coordination, cooperation and collaboration is essential, is decentrally organized in most relief chain networks. Strategic decisions are made at the headquarters level using information provided by the field. Tactical decisions are coordinated by headquarters located at regional, national and field levels. Operational decisions are quite often made in the field without any communication with others (Pedraza-Martinez and van Wassenhove 2012). People in charge of transport coordination have to decide on the number of vehicles, route planning, capacity of the vehicles and scheduling. Warehousing, as another field where coordination, cooperation and collaboration is required, deals with decisions regarding the number and location of distribution centers and relief camps during disasters. The available capacity of the facilities, the type of inventory and inventory policies are other relevant topics discussed in the context of warehousing coordination. The coordination of stakeholders in warehouse location decisions is influenced by location settings, logistics factors, national stability, costs and cooperation skills among all relief chain members (Roh et al. 2013). 
The absence of coordination, cooperation and collaboration within these decision-making processes may lead to undesired decisions, which can negatively impact beneficiaries' welfare, i.e. increase the number of victims. Disasters of recent years have made humanitarian organizations, governments and other aid providers more aware of the role of humanitarian logistics and the importance of coordination, cooperation and collaboration for efficient and successful emergency items procurement, transport and warehousing (Kovács and Spens 2007). A basic prerequisite for efficient coordination, cooperation and collaboration is a common understanding about the definitions and intents of these concepts among involved actors. It supports establishing appropriate measures and tasks in a structured manners without the need for clarification prior to actual process implementation. Especially in RSCM, where time is a critical component, the fast implementation without long-lasting dialogs is of utmost importance in order to react quickly. Nevertheless, there are observed disagreements in academia as well as practice on how to define coordination, cooperation and collaboration in the context of commercial supply chain management (SCM) and RSCM that cause turbulences among involved partners (Thomas et al. 2015). Some use the terms as synonyms or combine them, which leaves space for further interpretation. In this regard, academic literature does not offer satisfactory explanations. There are papers that tend to give an overview of existing literature in SCM and RSCM but they follow a rather global approach, not exclusively focusing on coordination, cooperation and collaboration and their definitions in SCM and RSCM (Chandraprakaikul 2010; John et al. 2012; Bag 2016; Leiras et al. 2014; Burgess et al. 2006; Power 2005). However, their contributions are highly relevant for gaining an overview about the broad spectrum of different topics in these research domains. To the best of our knowledge, literature reviews specializing on coordination, cooperation and collaboration and their definitions in SCM and RSCM have not been identified in academic literature. Obviously, deep insights into coordination, cooperation and collaboration in SCM and RSCM are not currently available, which constitutes the aim of this study. By means of a methodologically grounded literature review, we aim at clarifying the definitions of coordination, cooperation and collaboration in SCM and next analyze these concepts in the context of RSCM. In addition, this study maps current research activities in the field of coordination, cooperation and collaboration in SCM and RSCM and identifies important future research opportunities. In accordance with the objectives of this study, we have developed the following research questions:

RQ1 How can RSCM coordination, cooperation and collaboration be defined?

RQ2 How much research has been conducted in the field of SCM and RSCM focusing on coordination, cooperation and collaboration in recent years?

RQ3 Which research gaps and research potentials can be identified in SCM and RSCM with regard to coordination, cooperation and collaboration?

The paper is structured as follows: Next we draw attention to the characteristics of relief chain actors involved in RSCM and their engagement in RSCM 
coordination, cooperation and collaboration. In the third section, the applied methodology, i.e. systematic literature review, for identifying and analyzing relevant literature is discussed in detail. Afterwards, the results of the descriptive, qualitative and quantitative content analysis are presented, followed by a discussion on the topic and an outlook towards future research directions.

\section{Theoretical foundations of coordination, cooperation and collaboration}

The high complexity and volatility of natural and man-made disasters in recent years, e.g. the Tsunami in the Indian Ocean in 2004 or the refugee crisis in Middle and Eastern Europe in 2015, call for increased coordination, cooperation and collaboration between NGOs, governmental institutions and public-private partnerships in order to ensure adequate relief items supply for those in need (Schulz and Blecken 2010). The diversity of actors operating along a relief chain is extremely high, depending on the magnitude and severity of disasters. For example, in the 2004 Asian tsunami, more than 700 different NGOs were involved in disaster relief operations. Investigating this high number of diverse actors in more detail reveals three main stakeholder groups that contribute most to RSCM activities. They are represented by international agencies/NGOs, national agencies/NGOs and companies from the private sector (Balcik et al. 2010). Besides, donors and the military play a role in assisting humanitarian operations as they provide financial means, protect humanitarian assistance and enforce peace-making agreements (Heaslip et al. 2012). In order to maximize RSCM performance, the different relief actors have to strive for high levels of coordination, cooperation and collaboration during relief chain operations. Externalities, such as demand uncertainty, chaotic post-disaster environments, resource scarcity and disaster unpredictability are impediments that negatively affect coordination, cooperation and collaboration among relief chain stakeholders (Balcik et al. 2010). The lack of horizontal and vertical cooperation among relief supply chain parties often results in low efficiency and effectiveness, i.e. unshared resources, lost information or unstructured relief operations (Thomas and Kopczak 2005). Insufficient coordination and cooperation between humanitarian actors sometimes leads to excess supply in some regions and shortages in others (Duran et al. 2013; Schultz and Soreide 2008; Tatham et al. 2017). The lessons learned from past disasters have only had a minimum impact on the improvement of humanitarian coordination, cooperation and collaboration, because the unwillingness to embrace change, the reluctance to let down defenses and the competitive behavior of relief organizations still represent massive impediments for performance enhancements (McMaster and Baber 2012).

Another reason for performance impediments might be a common misunderstanding about the core aspects of coordination, cooperation and collaboration, because when talking about these terms, it is important to differentiate between them, as, according to Saab et al. (2008), each concept reflects a differing level of commitment, formality and autonomy. Nevertheless, the terms coordination, cooperation and collaboration are often used interchangeably and are placed on the same 
level (Zacharia et al. 2009; Sanchez Rodrigues et al. 2015). Various definitions of coordination, cooperation and collaboration have been published in recent years and the discussion about their interchangeability and connectivity is still ongoing in academia as well as among practitioners (Nolte et al. 2012). Especially, in realworld SCM, the line between coordination, cooperation and collaboration is not well drawn and the common understanding of what these concepts reflect is extremely fragmented. Analyzing academic definitions of coordination, cooperation and collaboration reveals the broad understanding of how to characterize these terms. Some researchers define coordination, cooperation and collaboration as complementary because they consist of similar elements (Kanda and Deshmukh 2008). Previous research does not explicitly distinguish between collaboration and coordination, such as Narus and Anderson (1996), who use collaboration to describe a cooperation among independent, but related firms to share resources and capabilities for customer satisfaction. Simatupang and Sridharan (2008) also provide mixed definitions, as they explain collaboration by using the term cooperation. According to their interpretation, collaboration is a close cooperation among independent business partners. Aside from mixed definitions, some researchers follow a stepwise and hierarchical approach in defining the terms. Therein, coordination is often seen as a prerequisite for cooperation and collaboration, as mentioned by Ergun et al. (2014). According to them, collaboration describes the relationship between partners whose operations and tasks are already coordinated. Coordination is sometimes also seen as the step after cooperation, as it is more formal than cooperation (Saab et al. 2013). Another stepwise approach describes coordination and cooperation as foundations for collaboration, as the latter presents the highest level of commitment, trust and information sharing (Soosay and Hyland 2015; Spekman et al. 1998). Kotzab et al. (2019) also go along with this approach and focus on the identification of the most important papers (by analyzing citation frequencies) and their interrelations in the context of SCM coordination, cooperation and collaboration. By using a bibliometric analysis the authors ask for the intellectual foundations of the three terms and reveal papers that form the basis for subsequent research and applied methodologies in this field. In comparison to our study, this paper differs in terms of context as we extend the analysis of the definitions coordination, cooperation and collaboration, taking the specialties of RSCM into consideration. What is rather scarce in academia is the concept that describes cooperation and collaboration as distinct approaches to coordinating interdependencies between firms and supply chain partners (Zacharia et al. 2009). As diverse as the various definitions are, so are the dimensions used to evaluate and differentiate between coordination, cooperation and collaboration. Criteria span from level of trust and commitment, relationship length, quality and closeness of the relationship, to level of intensity, willingness to share information, level of joint partnership management system, level of relationship specific asset and level of partner asymmetry (Spekman et al. 1998; Golicic et al. 2003; Keast et al. 2007; Kotzab et al. 2019).

From these various understandings of how to define coordination, cooperation and collaboration it can be concluded that academia does not fully agree on unique definitions (Thomas et al. 2015). Most RSCM researchers take the above mentioned definitions of coordination, cooperation and collaboration as given in their research, 
ignoring the characteristics of RCSM (e.g. high diversity of actors, information scarcity, chaotic post-disaster environment, demand, supply and disaster unpredictability) and their potential influence on defining these terms. In this regard, the highly diverse stakeholder portfolio (involving donors as well) may impact the definitions, as it is not always clear in disaster situations which partner is responsible for establishing coordination, cooperation and collaboration. The inherent information scarcity in relief chains may also impact the definitions because the level and quality of information in RSCM differ dramatically to SCM. Aside from this, the cycle times of response missions in RSCM are much shorter compared to processes and projects in SCM which might affect the time dimension in defining the terms. Not only cycle times but the external time pressure for responding rapidly in disaster situations is also considered to affect the temporal component in defining the terms. Moreover, the unpredictability of disasters and high demand and supply uncertainties may be reflected as, for instance, multiple processes (e.g. demand assessment, items procurement etc.) have to be considered in defining the terms.

\section{Methodology}

The applied methodology for answering the research questions in this paper is a systematic literature review structured in a qualitative and quantitative content analysis. In accordance with Fink (1998), a literature review "is a systematic, explicit and reproducible design for identifying, evaluating and interpreting the existing body of recorded documents". This scientific instrument enables researchers to illustrate the current state of research and provides the opportunity to identify important research

\begin{tabular}{|c|c|c|}
\hline \multirow[t]{2}{*}{$\begin{array}{l}\text { 1. Search- } \\
\text { string search }\end{array}$} & $\begin{array}{l}\text { Web of Science } \\
\text { (Thomson Reuters) }\end{array}$ & $\begin{array}{l}\mathrm{SCC} \\
\text { (Els }\end{array}$ \\
\hline & \multicolumn{2}{|c|}{ Redundant articles were filtered (Chadegani et al. 2013) } \\
\hline \multirow{3}{*}{$\begin{array}{l}\text { 2. Selection } \\
\text { of literature }\end{array}$} & \multicolumn{2}{|c|}{ Quality criteria I: VHB-ranking } \\
\hline & \multicolumn{2}{|c|}{ Quality criteria II: SCI-ranking } \\
\hline & \multicolumn{2}{|c|}{ Content criteria } \\
\hline $\begin{array}{l}\text { 3. Analysis } \\
\text { of literature }\end{array}$ & \multicolumn{2}{|c|}{ Final paper sample } \\
\hline
\end{tabular}

Fig. 1 Stages of the systematic literature review 
work based on citation frequencies and individually pre-defined criteria (Mayring 2003; Kunz and Reiner 2012). In the first step of the systematic literature review search-strings were developed and a search-string search was performed in the databases Web of Science (Thomson Reuters) and SCOPUS (Elsevier) for scientific papers (Step 1: Search-string search in Fig. 1). Here, the focus was put on papers that deal with SCM and RSCM between 1996 and 2015 to the same extent. From 2016 onwards, the focus was shifted to RSCM literature only due to the study's main focus of learning more about coordination, cooperation and collaboration of the field within recent years. Further, it supports the development of exclusive future research opportunities in the field of RSCM under consideration of latest publications. The combination of two databases supports the identification of relevant literature and offers greater coverage of the current research in the field of coordination, cooperation and collaboration in SCM and RSCM. The search output of both databases was scanned for redundant papers which were subsequently eliminated. Scientific papers that passed this initial step were filtered by publishing year and research domains in order to refine the search output (Klassen et al. 1998). Then, the two quality criteria were applied in order to reduce the sample size to high-quality papers. Our defined quality criteria state that papers for analysis had to be published in journals ranked in the VHB-ranking list (Quality criteria I) and the Science Citation Index (SCI) (Quality criteria II). Additionally, the papers had to meet the content criteria presented in Table 2 (Step 2: Selection of literature in Fig. 1). Finally, a descriptive, quantitative and qualitative content analysis was conducted (Step 3: Analysis of literature in Fig. 1). The following subsections highlight each processing step of the systematic literature review in detail (Fig. 1).

\subsection{Search-string search}

Guided by the expertise of librarians in the field of scientific databases we structured our search for relevant literature. In doing so, we combined the databases Web of Science (Thomson Reuters) and SCOPUS (Elsevier) in order to guarantee the greatest possible coverage of current scientific research. The literature search in Web of Science (Thomson Reuters) is the most common strategy for identifying influential papers in research, but the additional use of a second database supports the validity and reliability of findings (Delbufalo 2012). Within the two databases, the searchstrings searched the titles of English articles, as this is the universal language for international publications (Drubin and Kellogg 2012). The search-strings (Table 1) were developed by scanning abstracts and titles of relevant papers in a sample prior to the actual literature search being conducted. Central terms and synonyms were integrated in the search-strings in order to enhance the search output for influential scientific literature. The operators "AND" and "OR" were used to ensure the retrieval of a comprehensive output (Thorpe et al. 2005). The application of the search-string in Web of Science (Thomson Reuters) resulted in 600 potential academic papers and the search in SCOPUS (Elsevier) generated 537 scientific articles that deal with the topic addressed by this paper in a desired way. The fact that $2 / 3$ of all records can be found in both databases but $1 / 3$ is only included in one of these 
Table 1 Search-strings

\begin{tabular}{|c|c|}
\hline Database & Search-string \\
\hline $\begin{array}{l}\text { Web of Science (Thomson } \\
\text { Reuters) }\end{array}$ & $\begin{array}{l}\text { (Coo* OR collaboration) AND } \\
\text { humanitarian logistics OR (Coo* } \\
\text { OR collaboration) AND relief } \\
\text { chain OR (Coo* OR collabora- } \\
\text { tion) AND humanitarian chain } \\
\text { OR (Coo* OR collaboration) } \\
\text { AND disaster management OR } \\
\text { (Coo* OR collaboration) AND } \\
\text { disaster relief OR }(\text { Coo* OR } \\
\text { collaboration) AND supply chain } \\
\text { management OR Coo* AND col- } \\
\text { laboration OR cooperation AND } \\
\text { coordination OR collaboration } \\
\text { AND coordination }\end{array}$ \\
\hline SCOPUS (Elsevier) & $\begin{array}{l}\text { (Coo* OR collaboration) AND } \\
\text { humanitarian logistics OR (Coo* } \\
\text { OR collaboration) AND relief } \\
\text { chain OR (Coo* OR collabora- } \\
\text { tion) AND humanitarian chain } \\
\text { OR (Coo* OR collaboration) } \\
\text { AND disaster management OR } \\
\text { (Coo* OR collaboration) AND } \\
\text { disaster relief OR (Coo* OR } \\
\text { collaboration) AND supply chain } \\
\text { management OR Coo* AND col- } \\
\text { laboration OR cooperation AND } \\
\text { coordination OR collaboration } \\
\text { AND coordination }\end{array}$ \\
\hline
\end{tabular}

databases led to the elimination of redundant papers (Chadegani et al. 2013). Consequently, the initial number of 1137 articles could be reduced to a sample of 843 non-redundant papers.

\subsection{Selection of literature}

The 843 articles derived from the search-string search in the databases Web of Science (Thomson Reuters) and SCOPUS (Elsevier) constituted the basis for the further selection of pertinent literature. In accordance with our quality criteria, we only included papers that were published in a scientific journal ranked in the VHB-ranking list 2015 with a minimum rank of $\mathrm{C}$ and additionally listed in the Science Citation Index (SCI) 2014. As important articles are more likely to be published in leading journals, it makes sense to apply ranking lists in order to include such important publications in the analysis sample (Webster and Watson 2002). Journals listed in the VHB ranking listed from $\mathrm{A}+$ to $\mathrm{C}$ therefore represent an excellent to high quality publication standard. We excluded D ranked journals, as important journals in the field of SCM and RSCM are basically listed above C. Applying a second ranking list, in this case the Science Citation Index (SCI), minimizes bias and errors in 
Table 2 Inclusion and exclusion criteria

Inclusion criterion

Quality

The paper was published in a scientific journal ranked in the VHBranking list 2015 with $\mathrm{C}$ at the minimum and was additionally listed in the Science Citation Index (SCI) 2014
Articles that explicitly focus on cooperation, collaboration or coordination in the context of supply and relief chain management.

Content

Articles that intend to clearly describe the differences between cooperation, coordination and collaboration

Articles that provide definitions of cooperation, coordination or collaboration
Explanation

Our study aims to provide a broad overview about the state-ofthe-art in scientific research.

Nevertheless, the included material should fulfill specific quality requirements which can be ensured by using the impact factor in the Science Citation Index and the VHB-ranking list

In order to reveal potential research gaps with regard to cooperation, collaboration and coordination in supply and relief chain management it is important to find papers that deal with these aspects

This study tries to clarify the differences between cooperation, collaboration and coordination

This paper provides clear definitions of cooperation, collaboration and coordination

the selection process, thus leading to higher quality of the selection sample. Both, the VHB ranking list and SCI include all relevant journals in the field of SCM and RSCM (Klassen et al. 1998). Additionally, we analyzed papers published in the Journal of Humanitarian Logistics and Supply Chain Management, Voluntas: International Journal of Voluntary and Nonprofit Organizations and Disasters because of the relevant content for the systematic literature review. Aside from quality criteria we also defined content criteria in order to ensure that papers not only fulfill minimum journal quality but also include relevant content for our study. The content related prerequisite for papers to be included in the study was the explicit focus of coordination, cooperation or collaboration on SCM and RSCM. Papers that only highlighted the differences between coordination, cooperation and collaboration with respect to SCM were also taken into consideration in order to arrive at clear and proper definitions of these terms. Applying quality criteria on the one hand and content criteria on the other hand assures that only high-quality papers are included in the analysis. Table 2 summarizes our criteria for inclusion and exclusion of scientific articles. The application of the first quality criteria reduced the initial sample size to 372 articles in $\mathrm{A}+, \mathrm{A}, \mathrm{B}$ and $\mathrm{C}$ ranked journals. The second quality criteria application, resulted in a final number of 321 scientific articles that fulfilled both quality criteria. According to the predefined content criteria, we further filtered the papers based on their relevance to the topic by reading the abstracts and conclusions as proposed by Jahangirian et al. (2010). In doing so, the final number of scientific papers for the descriptive and content analysis was reduced to 202. The reason for the rejection of 119 further papers was that the defined search-strings were partly or 
fully reflected in the title of the 307 papers but the actual content did not meet the focus of our literature review precisely enough. For instance, the title of a certain paper contained the search-string elements "Coordination AND supply chain" but the content of this paper was related to the impact of liability rules on modes of coordination for food safety in supply chains.

\subsection{Analysis of literature}

Prior to the actual in-depth analysis of the paper contents, a descriptive analysis of the articles was conducted. This primarily served to numerically represent research activities in the field of SCM and RSCM coordination, cooperation and collaboration over time. The qualitative and quantitative content analysis was applied in order to answer the underlying research questions $R Q 1, R Q 2$ and $R Q 3$ in this study (Hsieh and Shannon 2005). Here, we followed an analysis approach called coding. From a methodological viewpoint, coding describes the process of deciphering and/or interpreting of data which is followed by a discussion and in-depth explanations (Mayring 2004). A code is a word, phrase or even paragraph that symbolically represents a portion of textual or visual data (Saldaña 2015). Generally, a coding sheet is used to collect codes and to structure the procedure of coding. In our coding we also made use of a coding sheet which served to evaluate and assess the 202 scientific articles regarding quantitative and qualitative information. On the one hand, the coding sheet served for collecting specialties of the terms coordination, cooperation and collaboration in SCM and RSCM. Therefore, the coding sheet contains dimensions that are represented in Tables 5, 6 and 9. In this regard, definitions that were presented in papers were analyzed in detail and coded according to the dimensions of the tables. Similar codes per dimension, i.e. information that shares commonalities, was combined and further discussed. On the other hand, the coding sheet is used for mapping the research landscape, to identify gaps for future research and to learn more about applied research methods by coding papers according to predefined categories presented in Tables 7 and 8. In the entire coding process, we were inspired by the coding approach proposed by Saldaña (2015). The software NVivo 11 was used for coding the scientific articles. In the software, the dimensions and categories of the tables (i.e. coding sheet) are represented by so called "nodes". Coding a paper according to the coding sheet in NVivo means that qualitative information from papers is assigned to nodes of the coding sheet, i.e. dimensions and categories of the Tables 5, 6 and 9. Technically speaking, a word, sentence or paragraph which is relevant to one or more dimensions and categories is assigned to a designated dimension (node in NVivo). Afterwards the coding software assigns a code to this word mark in order to structure the marked words.

As stated before, Tables 5, 6 and 9 served for answering $R Q 1$ in a structured way. The dimensions of these tables were specified by the authors in an informal analysis prior to the actual content analysis and seem to cover all relevant aspects for defining and differentiating between the terms coordination, cooperation and collaboration in commercial SCM and RSCM. Table 5 contains commercial SCM specific dimensions of coordination, cooperation and collaboration. Table 6 includes dimensions 
that are specific for coordination, cooperation and collaboration in RSCM and Table 9 depicts dimensions which are relevant for coordination, cooperation as well as collaboration in SCM and RSCM. These tables serve as an all-encompassing guide for analyzing the terms coordination, cooperation and collaboration for their general intent in SCM, their intent in RSCM, time horizon, phases of the disaster management cycle (DMC), critical factors in RSCM, structures and communication, authority, autonomy, resource allocation and risk sharing. The first dimension of Table 5 is related to the general intent of coordination, cooperation and collaboration in SCM. Here, each concept's purpose, motive and subject to be accomplished are captured. Basically, this dimension covers the Five Ws (Who, what, when, where and why) and reflects the core component of each concept. Meanwhile, the temporal component of each concept is further described in the category "time horizon". With temporal component we refer to the length of presence of each concept within supply chain partnerships. It is not directly linked to typical time parameters (e.g. days, weeks, months) but captured by supply chain specific elements. This constitutes the basis for the developed definitions presented in the last line of Table 5. The intent of coordination, cooperation and collaboration in RSCM and practical examples are illustrated in the dimension "Intent in RSCM" in Table 6. The dimension depicts the same information as in Table 5, considering the relief chain context. The next dimension "Time horizon" differs slightly compared to Table 5. As time in RSCM is often represented by different phases of the DMC, we categorize coordination, cooperation and collaboration along these phases ["Time horizon (DMC)"]. Each one of these phases consists of different core strategies and logistics operations required to react efficiently to challenges faced during and after a disaster. The mitigation phase, as a pre-disaster stage, refers to mechanisms and measures to reduce the overall vulnerability of a socio-economic system against negative external influences. The protective measures used in this phase are not directly linked to a specific disaster but serve as a supportive system for civil agencies, medical units and governmental facilities. The main objective of the subsequent preparation stage is the development of a physical logistics network design and communication technology systems to avoid the gravest possible consequences of a disaster. In this phase, the learning from past disasters and the adoption of already existing response strategies is of major importance. Once a disaster strikes, humanitarian logistics operations of the response phase are activated and immediately implemented in disaster relief. The main purpose of this stage is the activation of the "silent network" and to build up a coordination and logistics cluster within the first $72 \mathrm{~h}$ after disaster occurrence. The final stage "recovery" refers to operations in the aftermath (i.e. weeks and months) of a disaster. The logistics processes of this phase aim to support the process of recovery, i.e. debris removal and infrastructural reconstruction, and ensure a continuous return to pre-disaster conditions (Cozzolino 2012).

Critical drivers for successful coordination, cooperation and collaboration between NGOs are highlighted in the dimension "Critical factors in RSCM". In this regard, a critical driver for success is a factor or condition that remarkably impacts the reaching of a desired level of coordination, cooperation and collaboration. Identifying such critical factors in SCM is a common strategy for ensuring successful competitive performance along various dimensions (Ab Talib and Hamid 2014; 
Glenn Richey Jr et al. 2009). As the identification of such factors is also anticipated in this study we consider them in the analysis of literature and development of definitions. At the end of these two tables a corresponding definition of the terms coordination, cooperation and collaboration is provided. Table 9 continues the discussion of the terms and depicts information that is valid in both dimensions-SCM and RSCM. Here, the first dimension "Structures and communication" within each concept is focused on. The first aspect "Structure" is dedicated to the organizational interdependencies between organizations and intra-organizational structures when it comes to coordination, cooperation and collaboration in SCM and RSCM. It specifically asks for the way the different organizations perform tasks and activities between them and within their internal architectures. "Communication" refers to how interaction between organizations is established and which methods are used therefore. The second dimension "Authority" refers to ownership rights of organizations and describes the level of responsibility that they take on for tasks within coordination, cooperation and collaboration. Autonomy describes the state of self-governance of an organization and its capability to make decisions independently from others in the supply/relief chain (Lau et al. 2008). In the category "Resources and risks" information on how resources (i.e. tangible and intangible) and risks (operational, tactical and strategic) are treated within and among organizations is gathered. Here, we want to find out more about organizations' tendencies to share resources or rather restore them in coordination, cooperation and collaboration. The 202 papers were scanned and coded for definitions of coordination, cooperation and collaboration and further coded according to the categories of the tables. This served to answer $R Q 1$ and to present various definitions of coordination, cooperation and collaboration to sensitize the reader to the different semantics and meanings of these terms in SCM and RSCM. Proper definitions can be useful starting points for clear future research directions.

As mentioned earlier, the dimensions of Tables 7 and 8 served to answer $R Q 2$ in a structured way., Table 7 consists of two parallel dimensions, which are split into several subcategories. The two dimensions and included categories were defined based on the informal analysis of the content of the 202 papers. The most important topics in SCM and RSCM treated by academia are addressed by these dimensions. To identify areas of covered research $(R Q 2)$ the scientific articles are first classified according to their focus of research and further analyzed with respect to horizontal/vertical and centralized/decentralized coordination, cooperation and collaboration. As collaborative planning, forecasting and replenishment (CPFR) seems to be the most reasonable form of collaboration in supply chains, we also integrated this dimension in Table 7 (Barratt 2004; Soosay et al. 2008; Balcik et al. 2010; Krishnan and Winter 2009; Xiao et al. 2005; Ireland and Bruce 2000). Table 7 further incorporates strategies for improved coordination, cooperation and collaboration, such as contracting, incentive systems, pricing, information sharing and electronic data interchange (EDI) (Ma et al. 2013; Khouja et al. 2010; Chiou et al. 2007; Karabati and Sayin 2008; Hill and Scudder 2002). Coordination, cooperation and collaboration in the context of RSCM was also coded along the four stages of the DMC in order to gain an overview of scientific activity in this niche (van Wassenhove 2006). Related to $R Q 2$, we also paid attention to scientific methods used in the papers for 
gaining more knowledge on methodological preferences of the authors (Table 8). The identification of research gaps and potentials in SCM and RSCM with regard to coordination, cooperation and collaboration (RQ3) was conducted based on the quantitative results of the coding process (Table 7). Here, the coding along the dimensions allowed for multiple coding within and across dimensions in line with papers that focus on more than one topic. Afterwards, the instances of coding (quotes) per dimension were counted and integrated in Table 7. As pointed out by Spens and Kovács (2006) the main criticism directed at content analysis is the researcher's subjectivity in the coding process. In order to reduce subjectivity to a minimum several measures were applied during the content analysis which are summarized in Table 3. The assessment of the papers was carried out independently by two researchers in order to avoid any potential bias. The first researcher is a research associate focusing on the topic of humanitarian logistics in his research. The other researcher who was involved in the coding process is a research fellow with expertise in logistics and SCM. To ensure inter-rater reliability Cohen's Kappa was calculated with a value of 0.89 , which indicates the good quality of the coding process (Cohen 1960). The high value of the Cohen's Kappa can be attributed to the intensive discussions on the topic leading to a common understanding of the research aim. Besides, the researchers' similar level of knowledge and expertise in SCM supported the quality of the coding process, i.e. high Cohen's Kappa calculation. Examples for coding units are provided in the Appendix.

Table 3 Validity and reliability of the content analysis

Actions taken during content analysis

Transparency The coders followed a clear coding structure from the beginning of the coding for each category of frameworks I and II, e.g. a paper with clear focus on coordination in RSCM was firstly categorized as "research focus: RSCM coordination". Afterwards the paper content was further analyzed along the remaining categories, i.e. horizontal, vertical, centralized, decentralized, etc. For instance, if the paper with focus on RSCM coordination addresses decentralized aspects, it was additionally categorized as "decentralized" and a quote was added to the respective category in framework I

Validity 2a. In coding the papers, we strictly followed the pre-defined categories in the theoretical frameworks I and II

2b. Validity was further supported by a fine-tuning of the category development during the coding process. The coders came to the conclusion that pre-set categories were not exhaustive, thus leading to the introduction of the category "Risk" to framework I (Cullinane and Toy 2000)

Reliability 3a. In order to ensure the reliability of the coding instrument we set the coding structure for the categorization for each variable. (See transparency) (Milne and Adler 1999)

3b. Two independent coders were used during the content analysis for ensuring the reliability of the coded data (Cullinane and Toy 2000)

3c. For ensuring inter-rater reliability Cohen's Kappa was calculated (Cohen 1960)

$3 \mathrm{~d}$. The measurement reliability was ensured by discussing the assessment framework during the content analysis. Coders independently came to the result to include a further category "Risk" 


\section{Results}

\subsection{Results of the descriptive analysis}

Investigating the evolution and development of research on coordination, cooperation and collaboration in the context of SCM and RSCM constitutes the basis for further content analysis. The focus of interest was put on journal citation frequencies and the number of published articles per year. In terms of journal citation frequencies it is interesting to observe that $68 \%$ of the 202 scientific articles, e.g. 138 papers, stem from 11 different journals with citation frequencies above three. The remaining 64 papers were published in 40 different journals. Table 4 presents the number of papers published in the different journals and in Fig. 2 the papers are further sorted according to publishing year. Scientific research in the field of SCM and RSCM coordination, cooperation and collaboration started in the mid-90 s, was pushed in the early 2000s and became more and more important from the year 2009 onwards. Events, such as the outbreak of the Icelandic volcano Eyjafjallajökull in 2010, caused international supply chain disruptions, which called for enhanced cooperation and coordination along supply chains worldwide. Research communities became aware of the need for scientific research in order to achieve intensified supply chain cooperation and coordination. Especially in the context of humanitarian coordination, cooperation and collaboration, the increasing number of disasters (e.g. 9/11, earthquake Haiti 2004, etc.) all over the world acted as a major driver for intensified research efforts. Analyzing citation frequencies of included papers reveals that the most frequently cited contributions are by Balcik et al. (2010), Jahre and Leif-Magnus (2010), Nolte et al. (2012), Schulz and Blecken (2010) and Barratt (2004). The break in 2016 is due to the fact that from this year onwards we gave special attention to papers that exclusively deal with coordination, cooperation and collaboration in RSCM.

\subsection{Results of the qualitative content analysis}

In addition to the presentation of the descriptive results, this study aims to characterize and define the terms coordination, cooperation and collaboration in the context of commercial SCM and RSCM by assessing them along various dimensions. In order to distinguish the definitions of coordination, cooperation and collaboration we present the three aforementioned tables. From the diversity of definitions provided by academia it is obvious that the terms coordination, cooperation and collaboration cause turbulences in linguistic and scientific usage. As one contribution of this paper, the aim is to describe the terms coordination, cooperation and collaboration along a set of dimensions, to logically highlight their differences and to consider the unique setting of RSCM when developing their definitions. The information of each dimension in Table 5 is specific to commercial SCM and not directly transferable to the RSCM context. As the focus of this paper section is devoted to the detailed investigation of coordination, cooperation and collaboration in RSCM, 
Table 4 Number of publications per journal

Title of the journal

Number of

publications

International Journal of Production Economics (B)

European Journal of Operational Research (A)

International Journal of Production Research (B)

Production and Operations Management (A)

Supply Chain Management-An International Journal (B)

OMEGA (B)

Transportation Research Part E: Logistics and Transportation Review (B) 6

Journal of Operations Management (A)

Management Science (A+) $\quad 5$

International Journal of Operations and Production Management (B) 5

IIE Transactions (A) $\quad 4$

Benchmarking-An International Journal (C) 3

Decision Sciences (B) 3

Decision Support Systems (B) 3

Business Process Management Journal (C) 3

International Journal of Physical Distribution and Logistics Management (B) 3

Journal of Cleaner Production (B) 3

Naval Research Logistics (B) $\quad 3$

Journal of Business Logistics (B) 2

Industrial Marketing Management (B) 2

Computers and Operations Research (B) 2

International Review of Administrative Sciences (C) 2

Manufacturing and Service Operations Management (A) 2

Journal of Management Information Systems (A) 2

Journal of Manufacturing Technology Management (C) 2

International Journal of Business Research (C) 2

Voluntas: International Journal of Voluntary and Nonprofit Management 2

Disasters 2

Annals of Operations Research (B) $\quad 1$

Production Planning and Control (C) $\quad 1$

European Management Journal (B) $\quad 1$

$\begin{array}{ll}\text { Research Policy (A) } & 1\end{array}$

Journal of Humanitarian Logistics and Supply Chain Management 1

OR Spectrum (A) 1

Applied Economics (B) $\quad 1$

International Public Management Review (C) 1

Interfaces $(\mathrm{B}) \quad 1$

$\begin{array}{ll}\text { Logistics Research }(\mathrm{C}) & 1\end{array}$

Information and Management (C) $\quad 1$

Journal of Modelling in Management (C) $\quad 1$

Journal of Management Studies (A) 1

IEEE Transactions on Engineering Management (B) 1 
Table 4 (continued)

Title of the journal

Number of

publications

Asia-pacific Journal of Operational Research (C)

1

International Journal of Operations and Quantitative Management (C)

Administrative Science Quarterly $(\mathrm{A}+)$

1

Journal of Retailing (A)

Operations Research $(\mathrm{A}+)$

International Journal of Services and Operations Management (C)

International Journal of Logistics: Research and Applications (C)

Journal of the Operational Research Society (B)

Information Systems Frontiers (C)

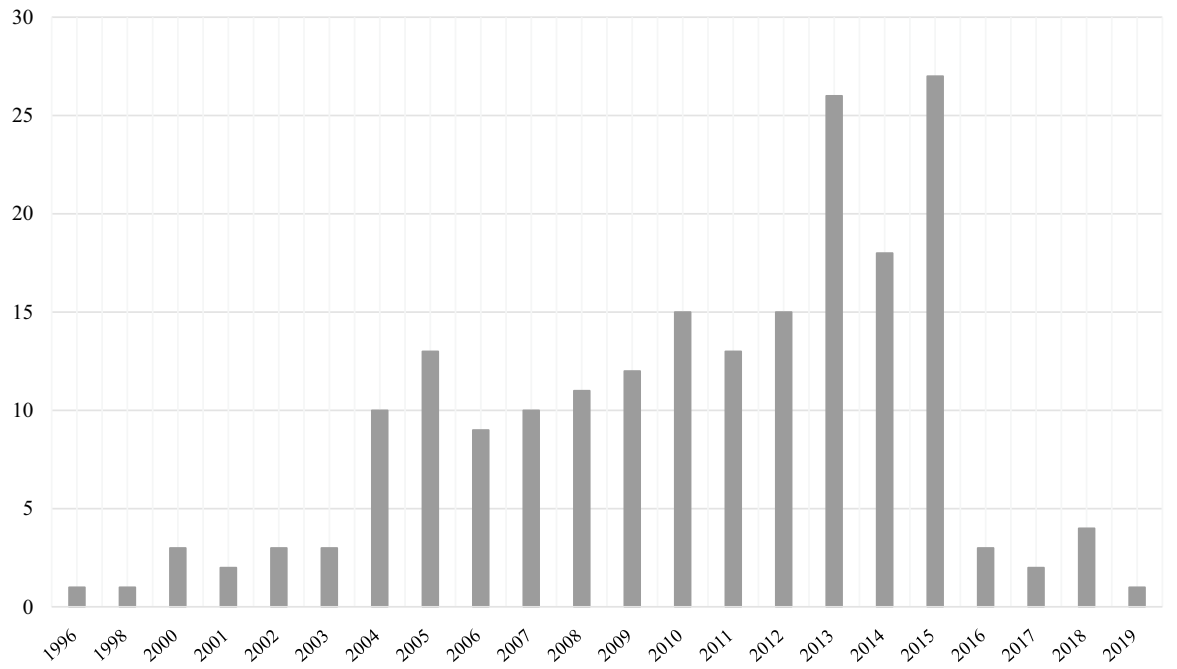

Fig. 2 Number of publications per year

an in-depth discussion of each category of Table 5 is waived. Instead we point to Table 6, which depicts dimensions specifically related to the terms coordination, cooperation and collaboration in RSCM.

The intent of coordination in RSCM is primarily the organization and alignment of NGOs' activities in the immediate response to disasters (Akhtar et al. 2012). This organizing, or harmonizing and adjusting refers to tasks, decisions, knowledge and funds in on-site demand assessment, procurement, installation and maintenance of water sanitation equipment, health facilities, search and rescue missions or disaster mapping (Maghsoudi et al. 2018). Coordination not only contains the organization of these operations but also the division and alignment of activities to participating NGOs. When disasters strike it is important and essential to identify NGOs' specializations in order to form clusters where NGOs with equal expertise can join 


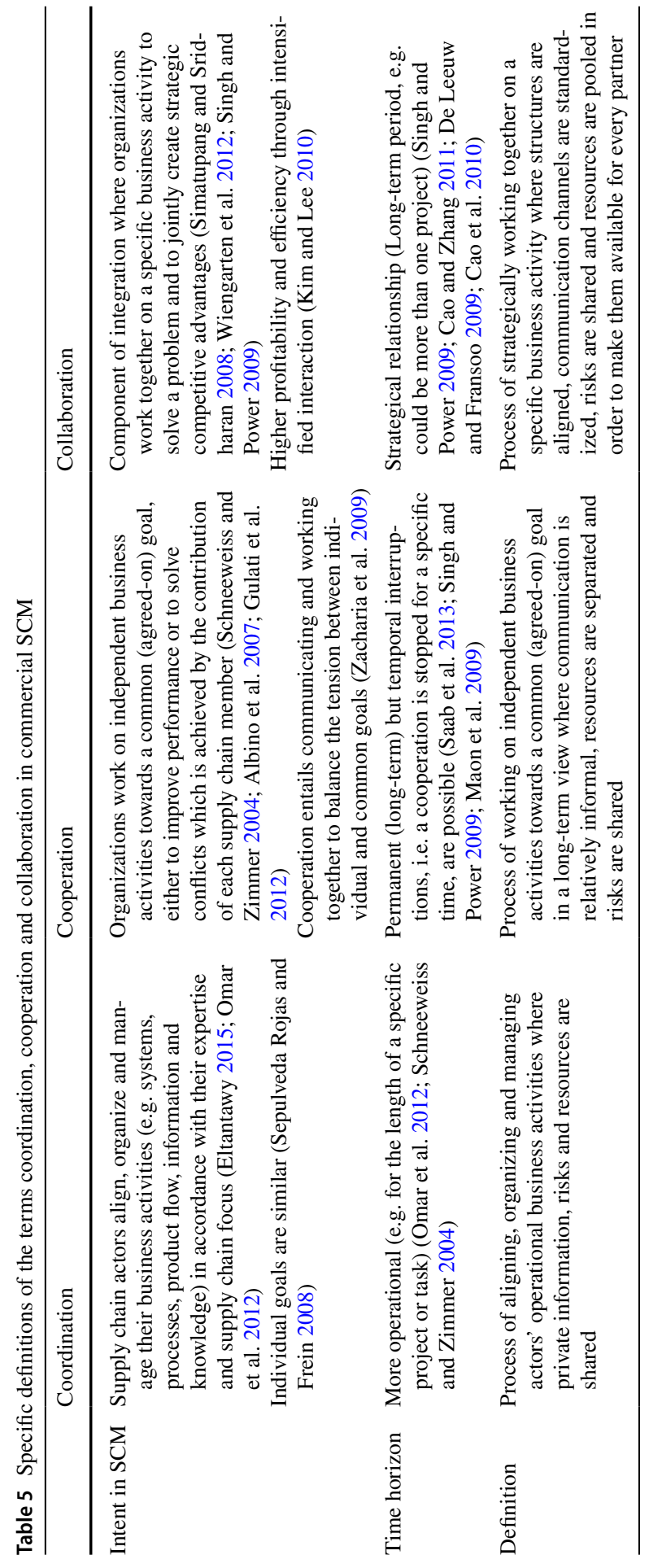




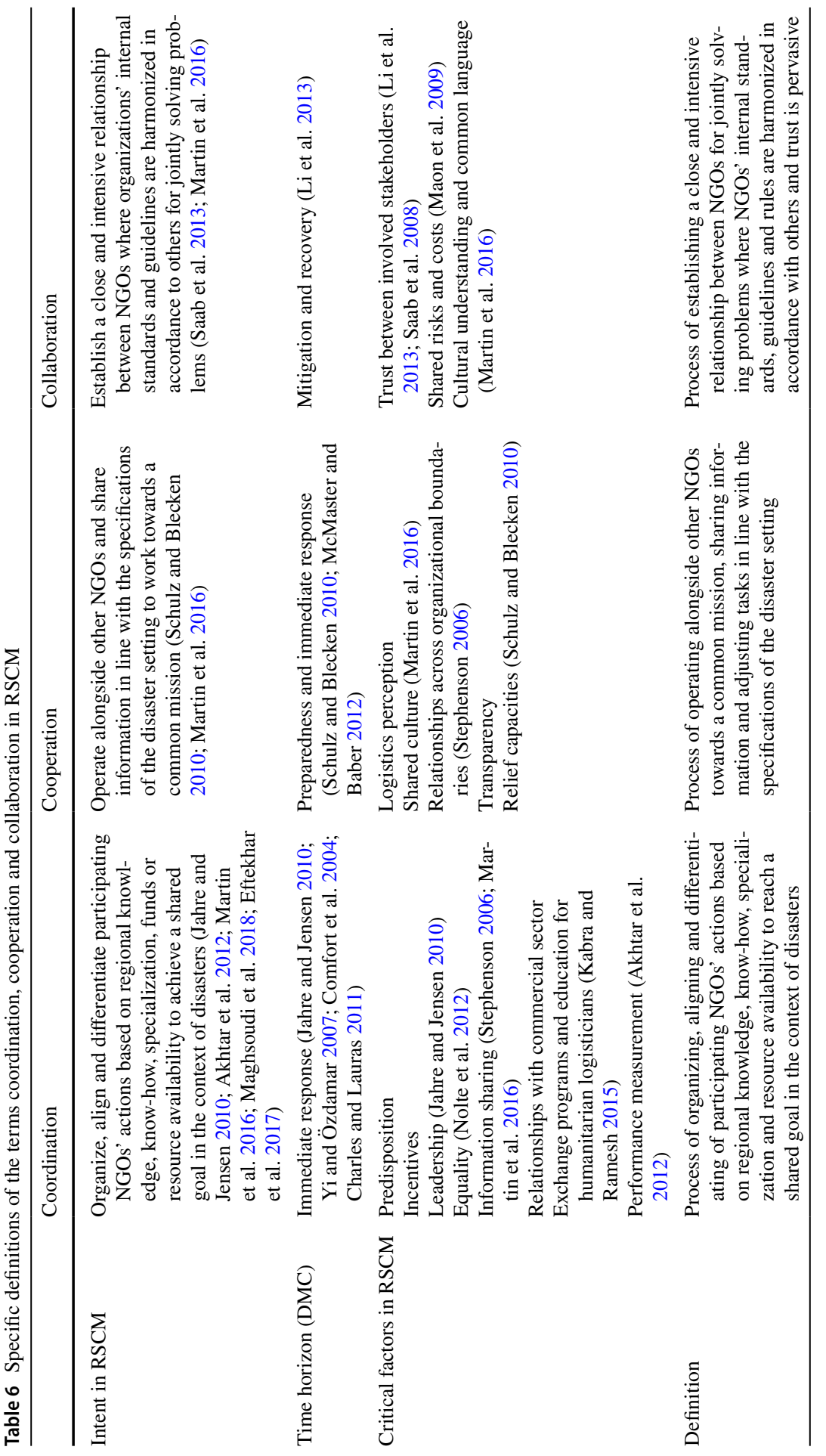




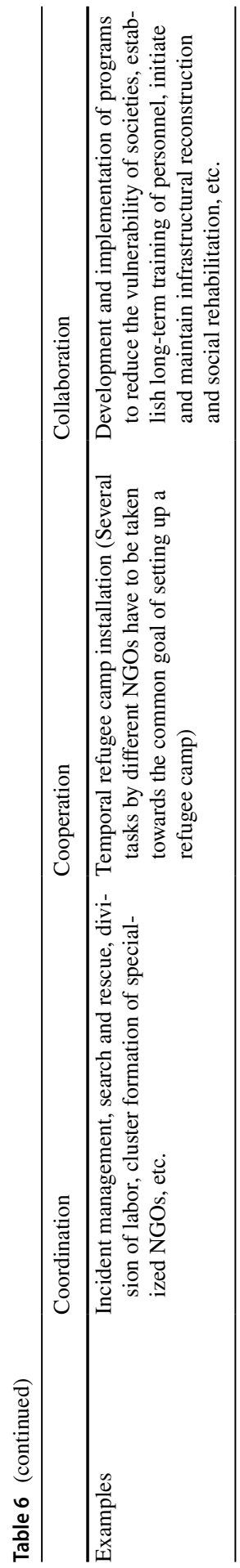


Table 7 Research landscape including the number of quotes per category

\begin{tabular}{|c|c|c|c|c|c|c|c|c|c|c|c|}
\hline & \multicolumn{4}{|c|}{ Supply Chain Management } & \multicolumn{4}{|c|}{ Relief Supply Chain Management } & & \\
\hline & & Coordination & Cooperation & Collaboration & Multiple & Coordination & Cooperation & Collaboration & Multiple & & \\
\hline & Research focus & 121 & 5 & 34 & 8 & 21 & 4 & 4 & 5 & & \\
\hline & Horizontal & 5 & 1 & 3 & 0 & 6 & 3 & 2 & 0 & & \\
\hline & Vertical & 8 & 2 & 3 & 0 & 4 & 2 & 1 & 0 & & \\
\hline & Centralized & 40 & 0 & 0 & 0 & 7 & 0 & 0 & 0 & & \\
\hline & Decentralized & 61 & 0 & 0 & 0 & $2^{*}$ & 0 & 0 & 0 & & \\
\hline & CPFR & 0 & 0 & 9 & 0 & 0 & 0 & 0 & 0 & & \\
\hline \multirow{6}{*}{ 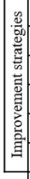 } & Contracting & 50 & 1 & 2 & 2 & 2 & $0^{*}$ & 0 & 0 & & \\
\hline & Incentives & 9 & 0 & 4 & 4 & 1 & $0^{*}$ & 0 & 0 & & \\
\hline & Pricing & 25 & 0 & 0 & 1 & 0 & 0 & 0 & 0 & & \\
\hline & Info-sharing & 18 & 2 & 9 & 2 & 5 & 1 & 0 & 2 & & \\
\hline & EDI & 5 & 0 & 5 & 0 & 0 & 0 & 1 & 2 & & \\
\hline & Risk-sharing & 5 & 0 & 1 & 1 & 0 & 0 & 0 & 0 & & \\
\hline & Challenges & 3 & 0 & 2 & 0 & 8 & 3 & 2. & 2 & & \\
\hline & & & & & & 1 & 0 & 0 & 0 & Mitigation & \\
\hline & & & & & & 5 & 0 & 0 & 0 & Preparedness & 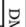 \\
\hline & & & & & & 15 & 2 & 0 & 3 & Response & है \\
\hline & & & & & & 1 & 0 & 1 & 0 & Recovery & \\
\hline
\end{tabular}

forces and exchange information for more efficient relief provision. Especially in the immediate response to a disaster, where time pressure is extremely high and urgent relief is needed, organizing and distributing emergency operations to humanitarian organizations is crucial for structured aid (Jahre and Jensen 2010; Yi and Özdamar 2007; Comfort et al. 2004; Charles and Lauras 2011). Several factors have to be considered in order to ensure effective and efficient RSCM coordination. Key components, including predisposition, incentives, leadership, equality, information sharing, commitment and trust, relationship specific investments and performance measurement enable powerful coordination among RSCM partners. Predisposition, which refers to tendencies and feelings towards potential partners, impacts RSCM coordination positively, when NGOs favor working together under extreme pressure in disaster scenarios. Incentives, i.e. benefits for structuring relationships in RSCM processes, motivate NGOs to share information and pool resources for handling the disaster more efficiently. Identifying leadership roles in the chaotic relief chain network is another factor that supports the efficient coordination of humanitarian stakeholders. Experienced leaders have the capacity, capability and knowledge to quickly identify roles within the humanitarian stakeholder network and clearly distribute tasks throughout contributing partners. Equality among the numerous organizations, i.e. similarity and reciprocity which organizations enjoy between them, improves the understanding of the joint mission and positively affects the perception of coordination throughout the relief chain network (Nolte et al. 2012). Performance measurement, as another critical factor, enables people in charge of coordination to continuously monitor current coordination efforts on the ground and thus make better decisions. It also helps NGOs to give feedback to others or own personnel and serves as motivator to better perform in future coordination missions (Akhtar et al. 2012). Coordination also requires fast information sharing, otherwise no knowledge about the disaster setting, available resources, NGO characteristics, etc. is present in the whole relief chain. Information sharing is often to be regarded as the most important factor among others to facilitate coordination (Martin et al. 2016). Information must be shared and distributed to all contributing NGOs to manage relief 
efforts and to avoid potential conflicts and duplication of efforts that might occur when information is not released (Stephenson, 2006). In order to ensure that proper information is shared, relationships of NGOs with the commercial sector, exchange programs and education for humanitarian logisticians are required (Kabra and Ramesh 2015). Close ties between NGOs and commercial sector companies helps them to be better prepared for stock-out situations in immediate response scenarios due to sufficient resource capabilities of commercial partners. Also, the joint training and education between NGOs can support their coordination performance by developing coordination strategies that fit every NGO's response concept. Once stable information channels are established, risks and uncertainty can be shared among organizations in equal measure, public availability is fostered and service quality can be improved (Eftekhar et al. 2017). Overall, coordination in RSCM is the process of organizing, aligning and differentiating of participating NGOs' actions based on regional knowledge, know-how, specialization and resource availability to reach a shared goal in the context of disasters.

Investigating the intent of cooperation in RSCM reveals that this term incorporates working together alongside other NGOs towards a common goal to provide humanitarian assistance adapted to the disaster setting (Schulz and Blecken 2010). Along the phases of the DMC, cooperation is often a short-term phenomenon, which is primarily established between NGOs in the preparedness and immediate response phases to disasters (Schulz and Blecken 2010; McMaster and Baber 2012). The development of joint preparedness activities, including evacuation plans or emergency items stocking is the subject of cooperation between NGOs in RSCM. Cooperation plays a key role in the immediate response to a certain disaster, as multiple organizations work on different tasks in order to satisfy beneficiaries' needs. Cooperation enables organizations to work together and to avoid duplication of efforts, which is quite often the case in such multi-player settings (Martin et al. 2016). A practical example includes the overall objective of installing a refugee camp where several NGOs contribute different operations to the setting up of a camp. Not only is coordination affected by key components, but cooperation is also influenced by a number of factors, such as field interaction, logistics perception, culture, relationships across organizational boundaries, transparency and relief capacities of NGOs. Logistics perception implies a common understanding of the role and relevance of logistics process for establishing cooperation between NGOs and other relief actors (i.e. governments, military). If all partners' perceptions towards logistics competence are harmonized, outsourcing of single logistics activities to more experienced NGOs can be conducted. In this regard, a continuous self-evaluation and reflection of core competences within NGOs is required. Another factor that impacts the level of cooperation is the internal culture lived by NGOs. The alignment of different visions, mission statements and principles of contributing NGOs benefits cooperation performance and avoids mistrust between them (Martin et al. 2016). Transparency with regard to NGOs' targets, cultures and strategies enhances cooperation quality, because individual NGO objectives are aligned faster and more clearly towards the common relief supply chain goal. Transparency of relief capacities, as another driver for successful cooperation, refers to whether NGOs have an overview of individual capacities or not. Here, disclosing and reporting of individual capacity 
levels to other NGOs is important for establishing cooperation between partners. It supports trust-building between NGOs and avoids stock-out situations and supply bottlenecks by timely interventions of partner NGOs. Setting up relationships across organizational boundaries at the staff level leverages the aforementioned factors and should therefore be fostered in every cooperation initiative (Stephenson 2006). To sum up, cooperation in RSCM describes the process of operating alongside other NGOs towards a common mission, sharing information and adjusting tasks in line with specifications of the disaster setting.

Collaboration between humanitarian stakeholders, as the last concept to be discussed, follows the intent to establish a close and intensive relationship (or alliance and coalition) between NGOs in order to jointly solve problems (Saab et al. 2013; Martin et al. 2016). Collaboration between NGOs is pursued in the mitigation and long-term recovery phases, where decisions are taken with particular caution and NGOs' strategies are adjusted to others without time pressure (Li et al. 2013). The most important driver for successful collaboration is trust. It is more than just sharing information and interfacing with other NGOs, because there is also the need to develop and prioritize trustful relations with other NGOs. Establishing trust between various partners leads to process integration and the interest to share benefits and costs. It is beyond doubt that trust is also important for coordination and cooperation but for long-term teamwork, i.e. collaboration, it is even more critical to trust other partners. Trust supports the pursuit of goals and specific output of relief chain operations, thus leading to high performance of relief chains (Saab et al. 2008; Li et al. 2013). Aside from contributing skill and resources, NGOs have to share risks and costs in a long-term perspective (Maon et al. 2009). These attributes may also impact cooperation, but they constitute the real basis for successful collaboration and continuous improvement in the humanitarian context. What is also important are cultural overlaps and shared ideologies between organizations, otherwise close and trusted relationships are hard to realize. A common language, which is reflected by shared opinions and conformity in decision-making, is another pillar for effective collaboration (Martin et al. 2016). In conclusion, collaboration in RSCM deals with establishing a close and intensive relationship between NGOs for jointly solving problems, where NGOs' internal standards, guidelines and rules are harmonized in accordance with others and trust is pervasive (Table 6).

\subsection{Results of the quantitative content analysis}

Another part of this study is constituted by the mapping of the scientific landscape in the areas of coordination, cooperation and collaboration SCM and RSCM. The reason for devoting attention to both dimensions can be explained by the relevance of scientific contributions in the field of SCM and their potential applicability to RSCM. With Table 7 we want to point to research areas, which have been fully or partially investigated and can thus help to shed more light on those, which remain basically undiscovered by scientific research to date. Thereby, a higher number of contributions in each dimension indicates a higher degree of research activities. For the purpose of visualization, we have highlighted a low number of quotes in green 
Fig. 3 Research focus of papers in SCM

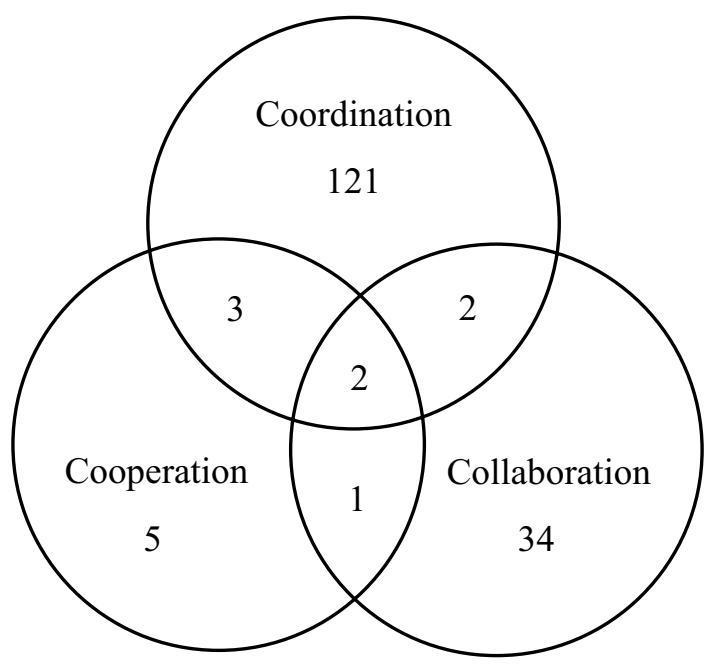

Fig. 4 Research focus of papers in RSCM

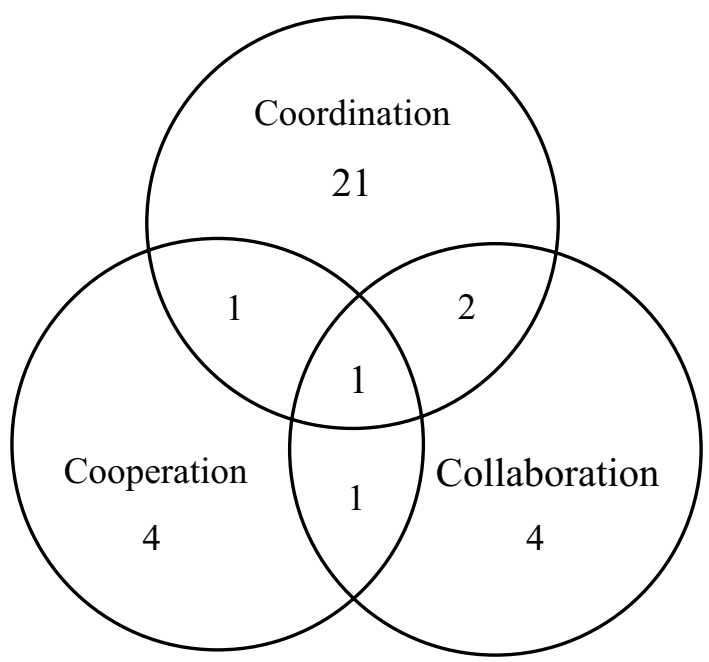

(0-9 quotes), a medium number of quotes in yellow (10-19 quotes) and a high number of quotes in red ( $\geq 20$ quotes).

Papers that do not exclusively focus on coordination, cooperation or collaboration, but treat at least two of them in combination, were assigned to category "Multiple" and also coded along the dimensions of Table 7. The Venn diagrams in Figs. 3 and 4 depict all possible sets of coordination, cooperation and collaboration and provide the exact number of papers for each set.

Exploring the distribution of all articles across the two main dimensions in Table 7, i.e. SCM or RSCM, reveals that the major part $(87 \%)$ deals with aspects of SCM. Supply chain coordination attracts the most attention among all 
dimensions (121 out of 202 articles). Cooperation in SCM and RSCM is not in the focus of research communities. The topics of centralization and decentralization are solely addressed in the context of supply chain coordination and are still undiscussed in RSCM. Strategies for improvement, such as contracting, incentive systems, pricing, information sharing and EDI are connected to a high degree with SCM with a special focus on coordination. Cooperation and collaboration are not linked to improvement strategies. As expected, CPFR is highly present in the dimension "Collaboration" but only with respect to SCM. Overall, papers devote attention to impact assessment of CPFR on overall supply chain performance, investigate the hurdles of efficient CPFR implementation, explore reasons for slow CPFR adoption and present conceptual frameworks to improve CPRF practice across supply chain partners. In the field of RSCM, no paper could be identified that treats CPFR in any way. The reasons behind this can only be guessed at but the imbalance of publication activities between SCM and RSCM is also apparent in this regard. According to the results of the quantitative content analysis they are also not addressed in RSCM. Surprisingly, previously tested improvement strategies for commercial supply chains are not brought into connection with the coordination of RSCM actors. One possible explanation might be that the increased complexity and volatility of RSCM activities deter researchers from applying improvement strategies in this area and testing their impact by scientific means. With regard to the DMC, RSCM coordination is well discussed in the immediate response phase after a disaster. Nevertheless, the need for further research in this area is highlighted due to its high potential for achieving faster and more efficient immediate disaster response coordination. Cooperation and collaboration issues are rather neglected and need to be further investigated in the context of RSCM. Challenges that are faced by stakeholders in coordination, cooperation and collaboration in the field of RSCM are attracting increasing attention from academia, as is observable in Table 7. The most attention is given to challenges in the preparedness and response to disaster, whereas they do not seem to be subject to research in the mitigation and recovery phases.

Aside from the contents of the 202 papers, we further aimed to gain more knowledge on methodologies applied within the research articles (Table 8). Table 8 presents a numerical overview of different research methods of the analyzed paper sample. The most frequently used methodology is represented by mathematical optimization, followed by qualitative case study research. Literature reviews, surveys and simulation studies are less frequently applied in these publications. Methodologies that did not fit any of the proposed categories (i.e. structural modeling, bayesian forecasting methodology, exploratory factor analysis, fuzzy analytic hierarchy process, etc.) are summarized in as "Others" (Table 8). The analysis of scientific methodologies indicates that quantitative analysis dominates research activities in the area of supply and relief supply chain coordination, cooperation and collaboration. 
Table 8 Quantitative overview of applied methodologies

\begin{tabular}{|c|c|}
\hline Research method & Count \\
\hline Optimization & 119 \\
\hline Case study & 34 \\
\hline Survey & 21 \\
\hline Simulation & 13 \\
\hline Literature review & 9 \\
\hline Others & 13 \\
\hline
\end{tabular}

\section{Discussion and future research}

Comparing coordination, cooperation and collaboration in SCM with RSCM shows that the context influences their definitions and equips them with a very special touch in the humanitarian setting. Coordination in both settings basically deals with organizing tasks (Eltantawy et al. 2015). In RSCM this organizing is extended by aligning and differentiating of NGOs' expertise in order to form clusters which allow the pooling of disaster management capabilities. Coordination of NGOs is performed as long as aid is needed and not limited to the length of a business activity, as it is the case for SCM. Coordinating NGOs' activities has to be in line with the beneficiaries' needs, the regional conditions and resource availability in the disaster region. The stakeholder landscape the organizations serve is completely different compared to SCM. Cooperative parties, whether they are represented by enterprises or NGOs, work on independent tasks towards a common goal, i.e. they act in a multidisciplinary setting. The tasks operated by NGOs are based on an entirely different context and horizontal and vertical cooperation between NGOs is not that easily established compared to SCM. According to the definition of collaboration in SCM it is the interdisciplinary process of strategically working together on a specific business activity with aligned structures and standardized communication (Simatupang and Sridharan 2008; Collin 2009). RSCM differs in terms of commitment and relationship intensity, because trust in RSCM is the major key to high-performance aid. NGOs have to build trust to others not only in emergency situations but also in the mitigation phases in order to design a robust and efficient aid network. Trust building in the humanitarian context plays a more critical role than in SCM, because beneficiaries' welfare can only be increased by trusting partnerships between NGOs. Trust is an essential component for team performance (Erdem and Ozen 2003). If trust is not present, teams cannot work efficiently. As the aim of humanitarian logistics is to alleviate suffering of disaster affected people, highly performing and trusted teams are of utmost importance. Here, networks are formed on the spot without long-term partnership building, which is different compared to commercial 
logistics and SCM processes where time is not that critical and trust can be built in a more time-relaxed environment (Tatham and Kovács 2010; Espada 2016). There is no doubt that trust is also important in SCM but the criticality of humanitarian logistics and RSCM (to support life-saving missions) definitely requires outstanding levels of trust between partners. Overall, it can be concluded that defining the terms coordination, cooperation and collaboration in RSCM requires contextual considerations, underlining their uniqueness in the disaster setting.

Discussing the developed definitions reveals that, despite their different contextual backgrounds, the terms coordination, cooperation and collaboration in SCM and RSCM have fundamental information in common. Table 9 includes information, which is valid for SCM and RSCM, thus not limited to only one context. A closer look at these similarities shows that stakeholders who coordinate their tasks are required to take specific roles in both settings, i.e. SCM or RSCM. Only the clear positioning of each stakeholder's' expertise and operational focus makes the structured coordination of tasks and procedures possible. Communication channels serve as a basis for structured interaction, which relies on formal governance and detailed contracts (Gulati et al. 2012). The individual authority rests with every stakeholder and tasks are performed fully autonomously, i.e. autonomy is preserved (Saab et al. 2013; Heydari 2014; Jahre and Jensen 2010). Stakeholders' resources are acknowledged, remain within every single organization and are made available to others (shared) on request (Simatupang and Sridharan 2002; Lambert et al. 1999; Ronchi et al. 2007; Eftekhar et al. 2017; Saab et al. 2008). Cooperation in SCM and RSCM is characterized by relatively informal communication, e.g. verbal communication, but contractual commitment is possible (Omar et al. 2012). It is relatively often established on a voluntary basis, whereby in RSCM the urgency of the disaster response makes organizations cooperate automatically in most cases (Martin et al. 2016). Authority again rests within every partner, which interacts without prejudice to their individual autonomy (Schulz and Blecken 2010; Saab et al. 2013; Albino et al. 2007). If cooperation between partners is initiated, their resources (human, financial, etc.) are separated to serve the individual organization's requirements, no matter if it is a commercial or humanitarian purpose (Mentzer et al. 2001). Collaboration in SCM and RSCM requires joint decision-making, development of strategic plans and synchronized operations, otherwise economic or humanitarian objectives cannot be reached (Soosay et al. 2008). Collaborative enterprises or NGOs standardize, formalize and make already created communication channels compatible and devise shared rules, norms and procedures (Kim and Lee 2010; Singh and Power 2009). They further see and understand the merits and benefits of close partnerships in both domains-SCM and RSCM (De Leeuw and Fransoo 2009). Unlike coordination and cooperation, the concept of collaboration makes organizations share their authorities and responsibilities for planning and implementing commercial or relief chain actions (Soosay et al. 2008, Omar et al. 2012; Saab et al. 2013). Comprehensive rules and norms restrict each enterprise's or NGO's autonomy when collaborating in a commercial or humanitarian network. Resources in both settings are pooled in order to open them for all stakeholders in case of urgent need (Soosay and Hyland 2015; Soosay et al. 2008; Cao et al. 2010). Finally, risks in SCM are shared to the 


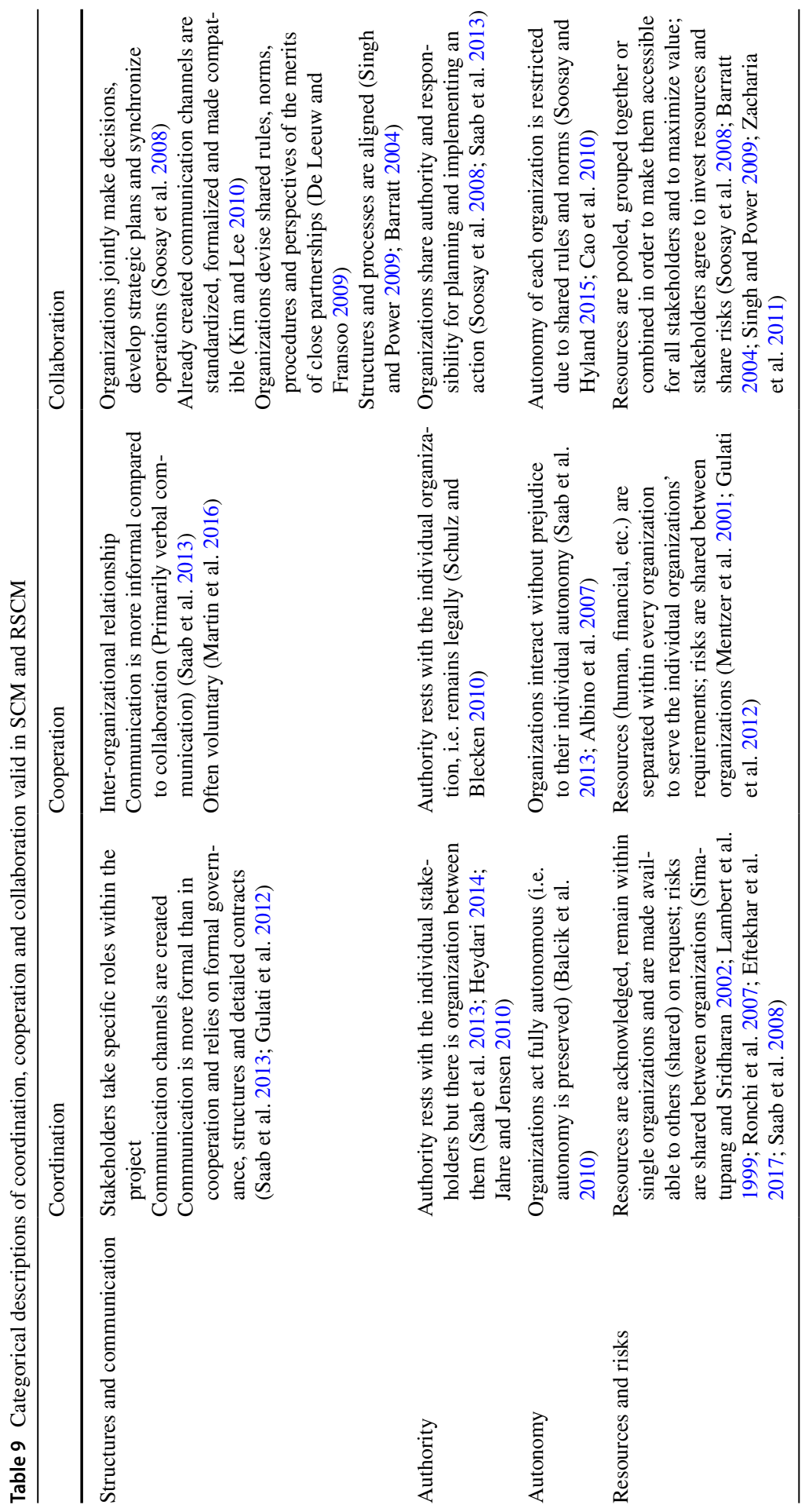


same extent as in RSCM, independent from coordination, cooperation or collaboration (Barratt 2004; Singh and Power 2009; Zacharia et al. 2011).

The examination of the results of the quantitative content analysis, i.e. Table 7 , reveals various research gaps in the scientific literature, which leave space for future investigation. Our study represents an attempt to motivate the research community to deepen the insight into certain topics related to coordination, cooperation and collaboration in RSCM. In this concluding section we present important directions for future research work in RSCM, as an additional result of the qualitative and quantitative content analysis. The results of the quantitative content analysis were used to identify these areas of low research activity and determine the direction of future research. The proposed research suggestions are based on article outlooks derived from the paper sample and are inspired by own individual perceptions in order to connect existing literature to these research opportunities. Further, they were supported by the results presented in Tables 5, 6 and 9, as the generated insights into the specifications of coordination, cooperation and collaboration in RSCM broadened our horizons in the development of future research opportunities. In fact, there is still a lot of open space for other research directions which are not covered by our ideas. In the following discussion we want to draw attention to decentralized decision-making in RSCM coordination, contracting in horizontal RSCM cooperation, and incentive alignment in RSCM collaboration as potential topics for future research (research gaps marked with * in Table 7).

\subsection{Research opportunity 1: decentralized decision-making in RSCM coordination}

Disasters of recent years, such as the tsunami in the Indian Ocean in 2004 or the terrorist attacks in New York in 2001, indicate that RSCM often lacks efficient and adequate coordination among all stakeholders involved in relief operations. Reasons for this can be explained by chaotic post-disaster environments, the high amount and diversity of relief actors or the absence of efficient resource allocation (Balcik et al. 2010). Coordination processes in relief chains are characterized by decentralized decision-making, i.e. decisions are made within single NGOs without sufficient transparency and the necessary willingness to share information and resources among all partners (Dolinskaya et al. 2011). In particular, the sharing of information deserves special attention due to its criticality for RSCM coordination (see dimension "Critical factors in RSCM" in Table 6). Moreover, the unwillingness to share resources on request from other organizations contradicts the common understanding of how to organize the sharing of resources and risks within SCM and RSCM coordination (see dimension "Resources and risks" in Table 9). Special focus should be put on procurement decisions, because they are often taken based on subjective perceptions of individual procurement agents, sometimes leading to excessive, wrong or insufficient supply quantities for beneficiaries. The inefficiencies in supply provision implicate that financial resources, which are limited in humanitarian organizations, are spent at locations where demand is already covered (Mc Guire 2015; Schultz and Soreide 2008; Duran et al. 2013). The increased scope and 
severity of today's disasters make the coordination of stakeholders in relief items procurement a challenging issue, which can no longer be handled by centralized and decentralized coordination approaches (Kapucu and Garayev 2011). Since the academic community and practitioners are calling for revised coordination strategies, alternative mechanisms need to be developed and integrated in RSCM. Such an alternative coordination strategy could be represented by distributed decision-making (DDM) which gives the opportunity to segregate complex multi-person decision problems into more tractable subsystems in order to achieve better overall performance in humanitarian operations. It implicates the distribution of decision-making authority throughout a larger group, where private information is shared and updated on a regular basis. This distribution of decision-making authority to individuals in a larger group is characteristic for coordination between stakeholders as presented in Table 9 (see dimension "Authority"). Each of the multiple group participants contributes to a final decision by performing one or more tasks in order to achieve a shared goal as intended in SCM and RSCM coordination (see dimensions "Intent in RSCM" in Table 6 and "Intent in SCM" in Table 5) (Ching et al. 1992). Especially in the immediate response after a disaster, the decision-makers can profit from a distributed decision-making network design due to reduced complexities of decisionmaking procedures (Schneeweiss 2002). Clearing houses may represent examples of such decision-making networks enabling NGOs on the one hand and suppliers on the other hand to coordinate procurement decisions transparently and with information symmetry. Innovative strategies, e.g. distributed decision-making, could offer the possibility to overcome uncoordinated leadership, failed communication and weak planning in relief chain operations (Donahue and Tuohy, 2006). Simulation modeling therefore may constitute the appropriate tool for scientific investigation, as for instance, system dynamics modeling in combination with agent-based simulation allow to simulate decision-making procedures in centralized, decentralized and distributed settings (Borshchev 2013).

\subsection{Research opportunity 2: contracting in horizontal RSCM cooperation}

RSCM is characterized by numerous actors operating on a horizontal basis in order to establish a working disaster management, as defined in Table 6 and described by Kovács and Spens (2007). In the immediate response to disasters, structured cooperation between stakeholders operating in the same stage of the relief chain is essential. The single organization's resources are limited and the risk of bottlenecks, i.e. capacity constraints, is always present. Other impediments for successful cooperation include the perception of logistics as one of the organization's core competences, lacking transparency regarding potential benefits of cooperation and cultural differences between NGOs (see dimension "Critical factors in RSCM" in Table 6). Identified impediments set the directions for future research activities for overcoming these hurdles (Schulz and Blecken 2010). In the long-term, those impediments represent critical factors that have to be controlled by means of adequate strategies. Therefore, the implementation of contracting between relief organizations may regulate cooperation initiatives in order to relax upcoming resource bottlenecks and to 
ensure efficient cooperation among all parties involved in RSCM. As revenue-sharing contracts in non-profit relief chains are not appropriate, cost-sharing contracts between different NGOs are proposed as alternative solution. Cost-sharing contracts would offer the possibility to reduce supply costs for single NGOs due to aggregated demand quantities and pooled transportation into disaster regions. To align interests and objectives of all parties at the same relief chain level, a horizontal strategic alliance can be formed. This contractual agreement ensures the risk sharing between two or more players located in the same stage of the relief chain which meets the standards on how risks are management in RSCM cooperation (see dimension "Resources and risks" in Table 9) (Verstreben et al. 2006). Contracting in a newsvendor problem can be modeled in order to compare the expected costs for NGOs in a traditional ordering environment with those that are generated under a cost sharing contract between NGOs.

\subsection{Research opportunity 3: incentive alignment in RSCM collaboration}

Motivating all participants in a relief chain to create value that benefits its actors and also the end-consumers, i.e. beneficiaries, is a challenging issue. Incentive alignment, including sharing costs, risks and benefits as critical success factors (see dimension "Critical factors in RSCM" in Table 6), harmonizes different objectives and enhances the overall RSCM collaboration performance in a long-term perspective (Simatupang and Sridharan 2008). Incentive systems in the humanitarian context should be in line with the overall objective to alleviate suffering and provide help where it is needed. Incentive systems in this regard must not motivate stakeholders to act opportunistically, i.e. increase their own profit. They should put the stakeholders' focus on performing efficiently based on society's welfare and not on individual enrichment. Furthermore, they might solve the problem of hidden information, which is present in almost every relief chain due to the opportunistic behavior of some stakeholders. Incentive systems should motivate stakeholders to collaborate, i.e. form coalitions, in the mitigation and long-term recovery phases, in order to overcome impediments related to present practice that is characterized by the exclusion of smaller NGOs and redundant relief items procurement. Besides, they facilitate joint decision-making and the establishment of structures that are characteristic for RSCM collaboration (see dimension "Structures and communication" in Table 9). Appropriate incentives encourage single stakeholders to participate in such procurement coalitions and to not only increase their own but also the overall RSCM performance. This strengthens close partnerships between NGOs and fosters joint problem solving without competitive behavior of single actors (see dimension "Intent in RSCM" in Table 6). However, competition within the commercial supply chain context is natural and desired up to a certain point. In relief supply chains, high levels of competition may have a negative impact on supply performance as the focus of operations is no longer put on the needs satisfaction process (Kovács and Spens 2010). In order to establish a healthy dose of competition within relief chains, incentive alignment may reduce the competitive thinking of NGOs. Rewards and punishments can differ from common SCM and may include financial support 
by governments or exclusion from disaster operations. To identify potential incentive systems for humanitarian supply chain purpose, case study research, including expert interviews, is proposed as the first step in this research direction. Adopting incentive systems from the commercial supply chain setting to RSCM is not recommended, due to the different stakeholder objectives and externalities.

\section{Conclusion}

The systematic identification and analysis of existing literature in the field of supply and relief supply chain coordination, cooperation and collaboration provide an overview of current scientific activities in this research area. The quantitative content analysis results show that coordination, cooperation and collaboration in the context of SCM are widely treated but they need to be given more attention in RSCM. As managerial contributions of the paper results are limited in the sense that practitioners on the ground can benefit from the comprehensive overview and analysis of critical factors impacting the effectiveness and efficiency of coordination, cooperation and collaboration in relief chains, attention should be given to the scientific paper contributions. The academic consideration of stabilizing the conceptual definitions of coordination, cooperation and collaboration adds clear value to the existing body of literature. Researchers are advised to put more emphasis on investigating improvement strategies for their effect on relief supply chain coordination, cooperation and collaboration, as findings may improve humanitarian operations. Based on the qualitative content analysis, this paper presents definitions of the terms coordination, cooperation and collaboration in SCM and RSCM. With this, the academic community is provided with accurate definitions of each concept. Contributions to academia are not only limited to the clarification of definitions but also include the results of the quantitative content analysis presented in the paper. In tabular form, they give other researchers a comprehensive overview of past and ongoing research activities in both domains, thereby illustrating a certain imbalance of research activities between SCM and RSCM. This could be reasoned by the fact that RSCM research is still in its infancy compared to SCM. This represents quite a valuable finding that should be used as a signal to stimulate interest in learning more about coordination, cooperation and collaboration in the relatively undiscovered field of RSCM. With our proposed research opportunities, we intend to leverage this process and give others initial ideas that can be followed in future research. With the research opportunities we not only contribute to academia by presenting potential research contents but also give advice on certain methods that could be applied in future research activities.

Our study is limited in the following ways. Firstly, the search-string search within paper titles may lead to a different number of papers compared to searching the whole manuscripts, but limiting it to a title search enhances the possibility to find more appropriate literature. Also, the single focus on papers in the field of coordination, cooperation and collaboration in RSCM from 2016 onwards constitutes another limitation of the study. We are fully aware of the fact that our decision to concentrate on journals ranked in both journal ranking lists [Web of Science (Thomson Reuters) and SCOPUS 
(Elsevier)] may lead to some missing publications in our analysis. The inclusion of relevant journals, which do not fulfill the quality criteria, reduces the risk of excluding important work. Another possible limitation of our study is related to the qualitative inclusion criteria. Abstracts and conclusions of papers are not always totally representative of their actual content and reading only these sections may result in the unintended exclusion of valuable contributions. However, our in-depth analysis of papers in which abstract and conclusion information did not completely meet the quality criteria, helped to reduce this potential bias. To conclude, the proposed research directions are motivated by paper outlooks derived from the paper sample and refined by individual perceptions. We know that other topics, e.g. relief chain resilience, are indirectly linked to the research opportunities, but due to spatial limitations these were not taken into consideration in the present discussion. As a conclusion, the identified gaps in the scientific literature indicate that further research and empirical testing is urgently required. The need for improved humanitarian logistics coordination, cooperation and collaboration is the major reason for devoting attention to further research in this field (Lasogga and von Ameln 2010). It is to be noted, that the focus of this study on coordination, cooperation and collaboration in both dimensions - SCM and RSCM-simultaneously, was motivated by the clear structural overlaps between SCM and RSCM. The confusion about the definitions in SCM and RSCM to the same extent, was another motivator that convinced us to give attention to both dimensions at the same time. We want to highlight, that our intention was not to exclusively analyze all the differences of definitions in great detail but using them as a basis to develop new definitions that incorporate elements of existing ones. This constitutes another limitation of our study which is of course interesting for future research. Future research could treat these concepts exclusively in RSCM for which our study constitutes a solid basis. The additional results of this study, i.e. proposed research avenues, therefore provide the initial impetus to intensify research efforts for investigating and elaborating innovative coordination, cooperation and collaboration approaches in RSCM.

Acknowledgements Open access funding provided by University of Klagenfurt.

Open Access This article is distributed under the terms of the Creative Commons Attribution 4.0 International License (http://creativecommons.org/licenses/by/4.0/), which permits unrestricted use, distribution, and reproduction in any medium, provided you give appropriate credit to the original author(s) and the source, provide a link to the Creative Commons license, and indicate if changes were made. 


\section{Appendix}

Content category Examples

Research focus: RSCM coordination

Decentralized SCM coordination

Information sharing in SCM collaboration
This paper describes an integrated location-distribution model for coordinating logistics support and evacuation operations in disaster response activities

The option contract in this paper enables the coordination of a relief supply chain and the achievement of Pareto improvement

The purpose of this paper is to identify chain coordinators and to explore their roles. The paper also highlights certain advantages of coordination, specific competencies of the coordinators, and challenges in the coordination

In this paper, we consider a similar coordination issue of a decentralized two-echelon supply chain

In the decentralized supply chain where the members belong to two different firms, the method of bargaining and negotiated solution which is dynamic in nature may result better coordination in the supply chain as compared to static coordinated solution in a centralized supply chain

The decentralized supply chain will be coordinated if both retailers exactly order the optimal production quantities, respectively. Hence, in order to coordinate the decentralized supply chain, we only need to design a mechanism that induces the retailers to offer the optimal retail prices of the centralized supply chain, respectively

In general, there is a trade-off in the kind of information required and the kind of information exchanged. This study analyses these trade-offs using an Analytic Hierarchy Process (AHP) model

We investigate two collaboration mechanisms: 'Too Little' and 'Too Late', depending on the timing of information sharing between the manufacturer and the retailer

The starting point of supply chain collaboration is information sharing. Information sharing aims to capture and disseminate timely and relevant information to enable decision makers to plan and control supply chain operations

Through an extensive literature review, it conceptualizes supply chain collaboration as seven interconnecting elements: information sharing, goal congruence, decision synchronization, incentive alignment, resource sharing, collaborative communication, and joint knowledge creation 


\begin{tabular}{ll}
\hline Content category & Examples \\
\hline Contracting in SCM cooperation/collaboration & This study investigates firms' R\&D cooperation behav- \\
& ior in a supply chain where two firms first cooperate \\
& in R\&D investments and then decide the production \\
quantity according to a wholesale price contract & We analyze the effect of contract leadership (i.e., the \\
& ability to offer wholesale price and two-part tariff \\
& contracts) on supply chain performance and use that as \\
& a basis to study coordination and cooperation
\end{tabular}

\section{References}

Ab Talib MS, Hamid ABA (2014) Application of critical success factors in supply chain management. Int J Supply C Manag 3:21-33

Akhtar P, Marr NE, Garnevska EV (2012) Coordination in humanitarian relief chains: chain coordinators. J Humanit Logist Supply C Manag 2:85-103

Albino V, Carbonara N, Giannoccaro I (2007) Supply chain cooperation in industrial districts: a simulation analysis. Europ J Oper Res 177:261-280

Bag S (2016) Humanitarian supply chain management: a bibliometric analysis of the literature. AIMS Int 10:175-202

Balcik B, Beamon BM, Krejci CC, Muramatsu KM, Ramirez M (2010) Coordination in humanitarian relief chains: practice, challenges and opportunities. Int J Prod Econ 126:22-34

Barratt M (2004) Understanding the meaning of collaboration in the supply chain. Supply C Manag Int J 9:30-42

Borshchev A (2013) The big book of simulation modelling. Multimethod modelling with Anylogic 6. Anylogic North America

Burgess K, Singh PJ, Koroglu R (2006) Supply chain management: a structured literature review and implications for future research. Int J Oper Prod Manag 26:703-729

Cao M, Zhang Q (2011) Supply chain collaboration: impact on collaborative advantage and firm performance. J Oper Manag 29:163-180

Cao M, Vonderembse MA, Zhang Q, Ragu-Nathan TS (2010) Supply chain collaboration: conceptualisation and instrument development. Int J Prod Res 48:6613-6635

Chadegani AA, Salehi H, Yunus M, Farhadi H, Fooladi M, Farhadi M, Ebrahim NA (2013) A comparison between two main academic literature collections: web of science and Scopus databases. Asian Soc Sci 9:18-26

Chandraprakaikul W (2010) Humanitarian supply chain management: Literature review and future research. Working paper, University of the Thai Chamber of Commerce, Bangkok, Thailand

Charles A, Lauras M (2011) An enterprise modelling approach for better optimisation modelling: application to the humanitarian relief chain coordination problem. OR Spectr 33:815-841

Ching C, Holsapple CW, Whinston AB (1992) Reputation, learning and coordination in distributed decision-making contexts. Org Sci 3:275-296

Chiou C, Yao M, Tsai J (2007) A mutually beneficial coordination mechanism for a one-supplier multiretailers supply chain. Int J Prod Econ 108:314-328

Cohen J (1960) A coefficient of agreement for nominal scale. Educ Psychol Measur 20:37-46

Collin A (2009) Multidisciplinary, interdisciplinary, and transdisciplinary collaboration: implications for vocational psychology. Int J Educ Vocat Guid 9:101-110

Comfort LK, Ko K, Zagorecki A (2004) Coordination in rapidly evolving disaster response systems: the role of information. Am Behav Sci 48:295-313

Cozzolino A (2012) Humanitarian logistics: cross-sector cooperation in disaster relief management. Springer Science \& Business Media

Cullinane K, Toy N (2000) Identifying influential attributes in freight route/mode choice decision: a content analysis. Transp Res Part E 36:41-53 
De Leeuw S, Fransoo J (2009) Drivers of close supply chain collaboration: one size fits all? Int J Oper Prod Manag 29:720-739

Delbufalo E (2012) Outcomes of inter-organizational trust in supply chain relationships: a systematic literature review and a meta-analysis of the empirical evidence. Supply C Manag Int J 17:377-402

Dolinskaya IS, Shi Z, Smilowitz KR and Ross M (2011) Decentralized approaches to logistics coordination in humanitarian relief. In: Proceedings of the 2011 industrial engineering research conference

Donahue AK, Tuohy RV (2006) Lessons we don't learn: a study of the lessons of disasters, why we repeat them, and how we can learn them. Homel Secur Aff 2:1-28

Drubin DG, Kellogg DR (2012) English as the universal language of science: opportunities and challenges. Mol Biol Cell 23:1399

Duran S, Ergun O, Keskinocak P, Swann JL (2013) Humanitarian logistics: advanced purchasing and pre-positioning of relief items. In: Bookbinder J (ed) Handbook of global logistics. Springer, New York, pp 447-462

Eftekhar M, Li H, Van Wassenhove LN, Webster S (2017) The role of media exposure on coordination in the humanitarian setting. Prod Oper Manag 26:802-816

Eltantawy R, Paulraj A, Giunipero L, Naslund D, Thute AA (2015) Towards supply chain coordination and productivity in a three echelon supply chain: action research study. Int J Oper Prod Manag 35:895-924

Erdem F, Ozen J (2003) Cognitive and affective dimensions of trust in developing team performance team performance management. Int J 9:131-135

Ergun Ö, Gui L, Heier Stamm JL, Keskinocak P, Swann J (2014) Improving humanitarian operations through technology-enabled collaboration. Prod Oper Manag 23:1002-1014

Espada F (2016) On authority and trust: a reflection on the effectiveness of disaster management in Bangladesh, India and Nepal. In: Espada F (ed.) Essays on humanitarian, Humanitarian Affairs Team and Humanitarian and Conflict Response Institute, London, pp 123-155

Fink A (1998) Conducting research literature review: from paper to the internet. Sage, Thousand Oaks

Glenn Richey Jr R, Chen H, Upreti R, Fawcett SE, Adams FG (2009) The moderating role of barriers on the relationship between drivers to supply chain integration and firm performance. Int J Phys Distri Log Manag 39:826-840

Golicic S, Foggin J, Mentzer J (2003) Relationships magnitude and its role in interorganizational relationship structure. J Bus Logist 24:57-76

Gulati R, Wohlgezogen F, Zhelyazkov P (2012) The two facets of collaboration: cooperation and coordination in strategic alliances. Acad Manag Ann 6:531-583

Heaslip G, Sharif AM, Althonayan A (2012) Employing a systems-based perspective to the identification of inter-relationships within humanitarian logistics. Int J Prod Econ 139:377-392

Heydari J (2014) Lead time variation control using reliable shipment equipment: an incentive scheme for supply chain coordination. Trans Res Part E Logist Trans R 63:44-58

Hill CA, Scudder GD (2002) The use of electronic data interchange for supply chain coordination in the food industry. J Oper Manag 20:375-387

Hsieh HF, Shannon SE (2005) Three approaches to qualitative content analysis. Qual Health Res 15:1277-1288

Ireland R, Bruce R (2000) CPFR. Supply c Manag re 1:80-88

Jahangirian M, Eldabi T, Naseer A, Stergioulas LK, Young T (2010) Simulation in manufacturing and business: a review. Eur J Oper Res 203:1-13

Jahre M, Jensen LM (2010) Coordination in humanitarian logistics through clusters. Int J Phys Distri Logist Manag 40:657-674

John L, Ramesh A, Sridharan R (2012) Humanitarian supply chain management: a critical review. Int J Ser Oper Manag 13:498-524

Kabra G, Ramesh A (2015) Analyzing drivers and barriers of coordination in humanitarian supply chain management under fuzzy environment. Benchmarking Int J 22:559-587

Kanda A, Deshmukh SG (2008) Supply chain coordination: perspectives, empirical studies and research directions. Int J Prod Econ 115:316-335

Kapucu N, Garayev V (2011) Collaborative decision-making in emergency and disaster management. Int J Pub Adm 34:366-375

Karabati S, Sayin S (2008) Single-supplier/multiple-buyer supply chain coordination: incorporating buyers' expectations under vertical information sharing. Eur J Oper Res 187:746-764

Keast R, Brown K, Mandell M (2007) Getting the right mix: unpacking integration meanings and strategies. Int Public Manag J 10:9-33 
Khouja M, Rajagopalan HK, Sharer E (2010) Coordination and incentives in a supplier-retailer rental information goods supply chain. Int J Prod Econ 123:279-289

Kim D, Lee RP (2010) Systems collaboration and strategic collaboration: their impacts on supply chain responsiveness and market performance. Decis Sci 41:955-981

Klassen TP, Jadad AR, Moher D (1998) Guides for reading and interpreting systematic reviews. I. getting started. Arch Pediatr Adolesc Med 152:700-704

Kotzab H, Darkow IL, Bäumler I, Georgi C (2019) Coordination, cooperation and collaboration in logistics and supply chains: a bibliometric analysis. Production 29

Kovács G, Spens K (2007) Humanitarian logistics in disaster relief operations. Int J Phys Distri Log Manag 37:99-114

Kovács G, Spens K (2010) Knowledge sharing in relief supply chains. Int J Netw Virtual Organ 7:222-239

Krishnan H, Winter R (2009) Inventory dynamics and supply chain coordination. Manag Sci 56:141-147

Kunz N, Reiner G (2012) A meta-analysis of humanitarian logistics research. J Humant Logist Supply Chain Manag 2:116-147

Lambert DM, Emmelhainz MA, Gardner JT (1999) Building successful logistics partnerships. J Bus Logist 20:165

Lasogga F, von Ameln F (2010) Kooperation bei Großschadensereignissen. Problemlagen und Entwicklungsperspektiven eines komplexen Organisationsnetzwerks. Gruppendynamik und Organisationsberatung 41:157-176

Lau HC, Agussurja L, Thangarajoo R (2008) Real-time supply chain control via multi-agent adjustable autonomy. Comput Oper Res 35:3452-3464

Leiras A, Brito I, Peres EQ, Bertazzo TR, Tsugunobu H (2014) Literature review of humanitarian logistics research: trends and challenges. J Humant Logist Supply Chain Manag 4:95-130

Li JP, Chen R, Lee J, Rao HR (2013) A case study of private-public collaboration for humanitarian free and open source disaster management software deployment. Decis Support Syst 55:1-11

Ma P, Wang H, Shang J (2013) Contract design for two-stage supply chain coordination: integrating manufacturer-quality and retailer-marketing efforts. Int J Prod Econ 146:745-755

Maghsoudi A, Zailani S, Ramayah T, Pazirandeh A (2018) Coordination of efforts in disaster relief supply chains: the moderating role of resource scarcity and redundancy. Int J Logist Res Appl 21:407-430

Maon F, Lindgreen A, Swaen V (2009) Designing and implementing corporate social responsibility: An integrative framework grounded in theory and practice. J Bus Ethics 87:71-89

Martin E, Nolte I, Vitolo E (2016) The four Cs of disaster partnering: communication, cooperation, coordination and collaboration. Disasters 40:621-643

Mayring P (2003) Qualitative Inhaltsanalyse. Weinheim und Base, Beltz Verlag, Germany, Grundlagen und Techniken

Mayring P (2004) Qualitative content analysis. In: Flick U, Von Kardoff E and Steinke I, A, Companion to qualitative research, pp 266-269

Mc Guire G (2015) Handbook of Humanitarian Health Care Logistics: Designing the Supply Network and managing the flows of information and health care Goods in humanitarian assistance during complex political emergencies in low-resource settings. 3rd edn

McMaster R, Baber C (2012) Multi-agency operations: cooperation during floodings. Appl Ergon 43:38-47

Mentzer JT, DeWitt W, Keebler JS, Min S, Nix NW, Smith CD, Zacharia ZG (2001) Defining supply chain management. J Bus Logist 22:1-25

Milne MJ, Adler RW (1999) Exploring the reliability of social and environmental disclosure content analysis. Acc Audit Account J 12:237-256

Narus JA, Anderson JC (1996) Rethinking distribution: adaptive channels. Har Bus Rev 74:112-120

Nolte IM, Martin EC, Boenigk S (2012) Cross-sectoral coordination of disaster relief. Public Manag Rev 14:707-730

Omar A, Davis-Sramek B, Myers MB, Mentzer JT (2012) A global analysis of orientation, coordination, and flexibility in supply chains. J Bus Logist 33:128-144

Pedraza-Martinez AJ, Van Wassenhove LN (2012) Transportation and vehicle fleet management in humanitarian logistics: challenges for future research. EURO J Transp Logistics 1:185-196

Power D (2005) Supply chain management integration and implementation: a literature review. Supply C Manag Int 10:252-263 
Roh SY, Jang HM, Han CH (2013) Warehouse location decision factors in humanitarian relief logistics. Asian J Shipp Logist 29:103-120

Ronchi S, Luzzini D, Spina G (2007) Supply chain coordination: the problem of risk and benefit sharing. Supply Chain Forum Int J 8:54-65

Saab DJ, Maldonado E, Orendovici R, Tchouakeu LM, Van Gorp A, Zhao K and Tapia AH (2008) Building global bridges: Coordination bodies for improved information sharing among humanitarian relief agencies. In: Proceedings of the 5th international iscram conference, Washington, DC, USA, pp 471-483

Saab DJ, Tapia A, Maitland C, Maldonado E, Tchouakeu LMN (2013) Inter-organizational coordination in the wild: trust building and collaboration among field-level ICT workers in humanitarian relief organizations. Voluntas 24:194-213

Saldaña J (2015) The coding manual for qualitative researchers. Sage, Newcastle upon Tyne

Sanchez Rodrigues V, Harris I, Mason R (2015) Horizontal logistics collaboration for enhanced supply chain performance: an international retail perspective. Supply C Manag Int J 20:631-647

Schneeweiss C (2002) Distributed decision making in supply chain management. Int J Prod Econ $84: 71-83$

Schneeweiss C, Zimmer K (2004) Hierarchical coordination mechanisms within the supply chain. Europ J Oper Res 153:687-703

Schultz J, Soreide T (2008) Corruption in emergency procurement. Disasters 32:516-536

Schulz SF, Blecken A (2010) Horizontal cooperation in disaster relief logistics: benefits and impediments. Int J Phys Distrib Logist Manag 40:636-659

Sepulveda Rojas JP, Frein Y (2008) Coordination and demand uncertainty in supply chains. Prod Plan C 19:712-721

Simatupang TM, Sridharan R (2002) The collaborative supply chain. Int J Logist Manag 13:15-30

Simatupang TM, Sridharan R (2008) Design for supply chain collaboration. Bus Process Manag J 14:401-418

Singh PJ, Power D (2009) The nature and effectiveness of collaboration between firms, their customers and suppliers: a supply chain perspective. Supply C Manag Int J 14:189-200

Soosay CA, Hyland P (2015) A decade of supply chain collaboration and directions for future research. Supply C Manag Int J 20:613-630

Soosay CA, Hyland PW, Ferrer M (2008) Supply chain collaboration: capabilities for continuous innovation. Supply C Manag Int J 13:160-169

Spekman RE, Kamauff JW Jr, Myhr N (1998) An empirical investigation into supply chain management: a perspective on partnerships. Supply C Manag Int J 3:53-67

Spens KM, Kovács G (2006) A content analysis of research approaches in logistics research. Int J Phys Distrib Logist Manag 36:374-390

Stephenson M (2006) Toward a descriptive model of humanitarian assistance coordination. Voluntas $17: 40-56$

Tatham P, Kovács G (2010) The application of "swift trust" to humanitarian logistics. Int J Prod Econ 126:35-45

Tatham P, Spens K, Kovács G (2017) The humanitarian common logistics operating picture: a solution to the inter-agency coordination challenge. Disasters 41:77-100

Thomas A and Kopczak LR (2005) From logistics to supply chain management: the path forward in the humanitarian sector. www.fritzinstitute.org/PDFs/WhitePaper/FromLogisticsto.pdf. Accessed Dec 2015

Thomas A, Krishnamoorthy M, Singh G, Venkateswaran J (2015) Coordination in a multiple producers-distributor supply chain and the value of information. Int J Prod Econ 167:63-73

Thorpe R, Holt R, Macpherson A, Pittaway L (2005) Using knowledge within small and medium-sized firms: a systematic review of the evidence. Int J Manag Rev 7:257-281

Van Wassenhove L (2006) Humanitarian aid logistics: supply chain management in high gear. J Oper Res Soc 57:475-489

Verstreben SF, Cruijssen M and Dullaert W (2006) A framework for horizontal cooperation in logistics. in: Proceedings of the ILS conference 2006, Lyon, France

Webster J, Watson RT (2002) Analyzing the past to prepare for the future: writing a literature review. MS Q 26:13-23

Wiengarten F, Pagell M, Fynes B (2012) Supply chain environmental investments in dynamic industries: comparing investment and performance differences with static industries. Int $\mathrm{J}$ Prod Econ 135:541-551 
Xiao T, Yu G, Sheng Z, Xia Y (2005) Coordination of a supply chain with one-manufacturer and two-retailers under demand promotion and disruption management decisions. Ann Oper Res 135:87-109

Yi W, Özdamar L (2007) A dynamic logistics coordination model for evacuation and support in disaster response activities. Eur J Oper R 179:1177-1193

Zacharia ZG, Nix NW, Lusch RF (2009) An analysis of supply chain collaborations and their effect on performance outcomes. J Bus Logist 30:101-123

Zacharia ZG, Nix NW, Lusch RF (2011) Capabilities that enhance outcomes of an episodic supply chain collaboration. J Oper Manag 29:591-603

Publisher's Note Springer Nature remains neutral with regard to jurisdictional claims in published maps and institutional affiliations. 